\title{
Loganiaceae no estado do Rio de Janeiro: chave para os gêneros e taxonomia de Spigelia
}

\author{
Loganiaceae in the state of Rio de Janeiro: \\ Key to the genera and taxonomy of Spigelia
}

\author{
Evelin Andrade Manoel ${ }^{1,5}$, Carlos Eduardo de Siqueira ${ }^{2}$, Marco Octávio de Oliveira Pellegrini ${ }^{3,4}$ \\ \& Elsie Franklin Guimarães ${ }^{4}$
}

\begin{abstract}
Resumo
Loganiaceae engloba cerca de 350 espécies em 13 gêneros com distribuição pantropical. Spigelia é um dos maiores gêneros da família, com cerca de 90 espécies e distribuição neotropical. No Brasil ocorrem 54 espécies, o que torna o país o centro de diversidade do gênero. A morfologia dos frutos de Spigelia já foi anteriormente abordada, entretanto, pouca ênfase foi dada à morfologia da porção basal diferenciada do fruto, o carpoatlas. O presente trabalho apresenta a chave para os gêneros da flora fluminense, e o tratamento taxonômico de Spigelia no estado do Rio de Janeiro, dando ênfase ao carpoatlas. Nove espécies são aceitas para o estado do Rio de Janeiro, sendo S. reflexicalyx reestabelecida no presente trabalho. Estas, são descritas, ilustradas e são apresentados comentários, mapa de distribuição e chaves de identificação. Tanto os carpoatlas quanto os forames e os estigmas, mostraram-se com formas e medidas diferenciadas entre as espécies.

Palavras-chave: carpoatlas, Flora fluminensis, Floresta Atlântica, Gentianales, Spigelieae.
\end{abstract}

\begin{abstract}
Loganiaceae includes about 350 species arranged in 13 genera with pantropical distribution. Spigelia, with ca. 90 Neotropical species, is one of the most diverse genera in the family. A total of 54 species of Spigelia are known to occur in Brazil, thusmaking the country the genus' diversity center. Fruit morphology in Spigelia has been already considered, nevertheless, little attention has been given to the morphology of the basal differentiated portion of the fruit, the carpoatlas. This study presents a key to the genera and the taxonomic treatment for Spigelia in the state of Rio de Janeiro, focusing on the morphology of the carpoatlas. Nine species are accepted, with $S$. reflexicalyx being reestablished in the present work. All species are described, illustrated and commented, together with a distribution map and an identification key. The carpoatlas, foramen and stigma were shown to vary greatly in shape and size among the studied species.
\end{abstract}

Key words: carpoatlas, Flora fluminensis, Atlantic Rainforest, Gentianales, Spigelieae.

\section{Introdução}

Loganiaceae R.Br. ex Mart. compreende 13 gêneros e cerca de 350 espécies pantropicais (Backlund et al. 2000; Heywood et al. 2007; The Plant List 2013). Está incluída em Gentianales, sendo facilmente diferenciada das outras famílias da ordem (i.e., Rubiaceae, Gentianaceae, Apocynaceae e Genselmiaceae) pela ausência de látex, cálice com prefloração valvar ou imbricada, e ovário súpero (Backlund et al. 2000; Heywood et al. 2007). No Brasil, a família é representada por cinco gêneros e 127 espécies, das quais 64 são endêmicas (BFG 2015). Spigelia contém ca. 90 espécies (The Plant List 2013), com distribuição exclusivamente neotropical, ocorrendo desde os Estados Unidos até a Argentina (Fernández Casa 2003). O Brasil é

\footnotetext{
${ }^{1}$ Universidade Federal do Rio de Janeiro, Inst. Biologia, Depto. Biologia Vegetal, Av. Carlos Chagas Filho 373, 21941-902, Rio de Janeiro, RJ, Brasil. evelin@ufrj.br / biorecados@gmail.com

${ }^{2}$ Fundação do Meio Ambiente do Estado de Santa Catarina, R. Felipe Schimt 485, 88010-001, Florianópolis, SC, Brasil. caduarte7@gmail.com

${ }^{3}$ Universidade de São Paulo, Depto. Botânica, R. do Matão 277, 05508-900, São Paulo, SP, Brasil. marcooctavio.pellegrini@gmail.com

${ }^{4}$ Instituto de Pesquisas Jardim Botânico do Rio de Janeiro, R. Pacheco Leão 915, 22460-030, Rio de Janeiro, RJ, Brasil. eguimar@jbrj.gov.br

${ }^{5}$ Autor para correspondência: evelin@ufrj.br
} 
o centro de diversidade para o gênero, onde ocorrem 54 espécies, ca. $60 \%$ de todo o gênero. No Brasil, Spigelia é especialmente diverso nas formações de Campos Rupestres e Floresta Ombrófila Densa (Zappi 2005; Zappi 2006; BFG 2015). O gênero se caracteriza pelo hábito herbáceo ou raramente subarbustivo, folhas opostas ou verticiladas, inflorescências em cimeiras escorpioides, flores pentâmeras sésseis a subsésseis, sépalas livres ou conatas na base com coléteres na face adaxial, corola geralmente de cores brilhantes, tubular a infundibuliforme, estilete filiforme articulado na porção mediana inferior, e cápsulas fortemente bilobadas com metaestilete e carpoatlas persistentes (Fernández Casa 2003).

Apesar dos trabalhos existentes sobre a morfologia de Spigelia (Guimarães \& FontellaPereira 1969; Zappi 2005; Zappi 2006), pouco se relata sobre detalhes morfológicos do seu fruto e principalmente, da parte basal do mesmo. Fernández Casa (2003) realizou um amplo estudo carpológico em Spigelia, caracterizando o fruto e estabelecendo a terminologia para a sua porção basal (i.e., carpoatlas). $\mathrm{O}$ autor descreve em detalhes as partes do carpoatlas, o metaestilete e a morfologia geral das cápsulas. Segundo o mesmo, o carpoatlas representa uma porção espessada da cápsula de Spigelia. Essa estrutura é provida de uma perfuração central (o forame) e é a única porção do fruto que permanece presa ao receptáculo, após sua deiscência.

No presente trabalho, foram analisados os carpoatlas de todas as espécies de Spigelia ocorrentes no estado do Rio de Janeiro (Fig. 8). Essa análise teve como objetivo explorar o potencial sistemático desse importante caráter na taxonomia do gênero. Como resultado da análise carpológica, apresentamos o tratamento taxonômico do gênero no estado do Rio de Janeiro, com uma chave de identificação, descrições, ilustrações, mapa de distribuição e uma tabela comparativa de caracteres carpológicos. Apresenta-se também a descrição para a família Loganiaceae e chave para os gêneros no estado do Rio de Janeiro.

\section{Materiais e Métodos}

Foram realizadas coletas no período de abril/2005 a abril/2007, em diferentes municípios do estado do Rio de Janeiro. As coletas foram feitas preferencialmente nos meses de setembro a janeiro, período de floração das espécies. Em campo foram observadas e anotadas as características vegetativas e reprodutivas. As plantas coletadas foram fotografadas, prensadas e desidratadas em estufas a $70^{\circ} \mathrm{C}$, por 48 horas. Para as análises morfológicas e elaboração das ilustrações, as peças florais e frutos foram conservados em álcool etílico a 70\%.

Para a identificação das espécies foram utilizadas as obras de Guimarães \& Fontella-Pereira (1969), Progel (1868) e Cronquist (1981), além de comparações com exemplares tipos e imagens digitais. As espécies são apresentadas em ordem alfabética, todas com comentários, ilustrações e informações sobre a distribuição geográfica, com base em coleções de herbário e literatura. Os dados de habitat e fenologia das espécies foram levantados a partir das anotações de campo e das coleções analisadas. Neste estudo foram examinados espécimes, incluindo tipos depositados nas instituições nacionais e estrangeiras, designadas pelos acrônimos (Thiers, continuamente atualizado): B, BR, ESA, G, GUA, HAL, HUEFS, K, M, MBM, MO, NY, P, R, RB, RFFP, SP, SPF, UB, UEC, US e VIC. Para todas as espécies, foram analisados espécimes provenientes de todas as localidades com registros de ocorrência no território brasileiro. Materiais de outros estados foram incluídos no presente trabalho, apenas quando os espécimes da flora do estado eram insuficientes para a confecção de uma descrição que abrangesse a variação da espécie. A terminologia carpológica segue Fernández Casa (2003), a forma da lâmina foliar e os padrões de nervação seguem Hickey (1974) e Rizzini (1977). Seguiu-se IBGE (2012) para a designação dos tipos de vegetação.

O mapa de distribuição geográfica das espécies foi construído com o software QGIS (disponível em < http://www.qgis.org $>$ ), com base nas coordenadas dos materiais depositados nas coleções dos herbários anteriormente citados. Para os registros sem coordenadas especificadas foram utilizadas as coordenadas do centro do município obtidas através da ferramenta geoLoc (disponível em $<$ http://splink.cria.org.br/geoloc $>$ ). Os dados de distribuição geral das espécies foram retirados de literatura e complementados com dados de materiais analisados.

\section{Resultados e Discussão}

Um total de nove espécies de Spigelia são reconhecidas para a flora do estado do Rio de Janeiro sendo uma delas aqui reestabelecida. Apesar do estado do Rio de Janeiro ser um dos estados mais bem coletados (BFG 2015), o número de espécimes de Spigelia encontrados nos herbários visitados se mostrou bastante baixo (vide o pequeno número de 
espécimes citado no material examinado). Isso pode ser um indicativo da raridade do grupo no estado do Rio de Janeiro, ou de falta de coletas direcionadas ao grupo.

Além dos caracteres tradicionalmente utilizados para a delimitação de espécies em Spigelia (i.e., filotaxia, forma e consistência das folhas, presença e ausência de pecíolo, morfologia de inflorescência e indumento), outros caracteres apresentaram relevância taxonômica. A forma do caule, o grau de conação dos lacínios do cálice, a presença de estrias na face interna da corola, a forma das anteras e o número e coloração das sementes se mostraram significativos para diferenciar alguns grupos de espécies. Os caracteres carpológicos, se mostraram bastante importantes para os estudos sistemáticos em Spigelia. Apenas utilizando caracteres carpológicos, é possível separar todas as espécies registradas para o estado do Rio de Janeiro (Tab. 1; Fig. 8). Caracteres como tamanho

Tabela 1 - Caracteres carpológicos.

Table 1 - Carpological characters.

\begin{tabular}{|c|c|c|c|c|}
\hline Espécie & Estigma & Metaestilete & Carpoatlas & Forame \\
\hline S. beyrichiana & $\begin{array}{l}\text { 4-4,3 mm de compr., } \\
\text { ápice obtuso, levemente } \\
\text { papiloso, papilas } \\
\text { triangulares }\end{array}$ & $\begin{array}{l}\text { 2,5-4 mm } \\
\text { compr., zona } \\
\text { de abscisão } \\
\text { arredondada }\end{array}$ & $\begin{array}{l}3,5-8 \times 2,5-6,4 \mathrm{~mm} \text {, } \\
\text { elíptico, extremidades } \\
\text { obtusas }\end{array}$ & $\begin{array}{l}1,5-1,7 \times 1,4-1,5 \mathrm{~mm}, \\
\text { arredondado }\end{array}$ \\
\hline S. flemmingeana & $\begin{array}{l}\text { 2-2,5 mm compr., ápice } \\
\text { agudo, densamente } \\
\text { papiloso, papilas } \\
\text { lanceoladas }\end{array}$ & $\begin{array}{l}\text { 1-2,2 mm } \\
\text { compr., zona } \\
\text { de abscisão } \\
\text { elíptica }\end{array}$ & $\begin{array}{l}1,8-2 \times 1-1,4 \mathrm{~mm}, \\
\text { rômbico-elíptico, } \\
\text { extremidades agudas }\end{array}$ & $\begin{array}{l}0,7-0,9 \times 0,25-0,3 \mathrm{~mm} \text {, } \\
\text { elíptico }\end{array}$ \\
\hline S. laurina & $\begin{array}{l}\text { 4-4,5 mm compr., } \\
\text { ápice obtuso, levemente } \\
\text { papiloso, papilas } \\
\text { triangulares }\end{array}$ & $\begin{array}{l}\text { 8-10 mm } \\
\text { compr., zona } \\
\text { de abscisão } \\
\text { elíptica }\end{array}$ & $\begin{array}{l}3,5-4 \times 2-2,2 \mathrm{~mm} \text {, } \\
\text { elíptico, extremidades } \\
\text { obtusas a truncadas }\end{array}$ & $\begin{array}{l}0,9-1 \times 0,8-1 \mathrm{~mm}, \\
\text { elíptico }\end{array}$ \\
\hline S. macrophylla & $\begin{array}{l}0,8-1,3 \mathrm{~mm} \text { compr., ápice } \\
\text { agudo, papiloso, papilas } \\
\text { triangulares }\end{array}$ & $\begin{array}{l}0,8-2 \mathrm{~mm} \\
\text { compr., zona } \\
\text { de abscisão } \\
\text { elíptica }\end{array}$ & $\begin{array}{l}2,5-3,2 \times 1,8-2 \mathrm{~mm} \text {, } \\
\text { largo rômbico-elíptico, } \\
\text { extremidades agudas }\end{array}$ & $\begin{array}{l}1 \times 0,9-1 \mathrm{~mm} \text {, } \\
\text { arredondado }\end{array}$ \\
\hline S. pusilla & $\begin{array}{l}\text { 2,2-3 mm compr., ápice } \\
\text { agudo, densamente } \\
\text { papiloso, papilas } \\
\text { lanceoladas }\end{array}$ & $\begin{array}{l}\text { 1-1,2 mm } \\
\text { compr., zona } \\
\text { de abscisão } \\
\text { elíptica }\end{array}$ & $\begin{array}{l}3,6-4 \times 1,4-1,6 \mathrm{~mm} \text {, } \\
\text { elíptico, extremidades } \\
\text { emarginadas }\end{array}$ & $\begin{array}{l}0,5-0,6 \times 0,5-0,6 \mathrm{~mm}, \\
\text { arredondado }\end{array}$ \\
\hline S. reflexicalyx & $\begin{array}{l}\text { 2-2,8 mm compr., ápice } \\
\text { agudo, papiloso, papilas } \\
\text { lanceoladas }\end{array}$ & $\begin{array}{l}1-1,5 \mathrm{~mm} \\
\text { compr., zona } \\
\text { de abscisão } \\
\text { elíptica }\end{array}$ & $\begin{array}{l}3,5-4,2 \times 1,6-1,8 \mathrm{~mm} \text {, } \\
\text { rômbico-elíptico, } \\
\text { extremidades acuminadas }\end{array}$ & $\begin{array}{l}0,9-1 \times 0,5-0,6 \mathrm{~mm} \text {, } \\
\text { elíptico }\end{array}$ \\
\hline S. scabra & $\begin{array}{l}\text { 2,2-3,1 mm compr., } \\
\text { ápice agudo, densamente } \\
\text { papiloso, papilas } \\
\text { lanceoladas }\end{array}$ & $\begin{array}{l}0,9-1,4 \mathrm{~mm} \\
\text { compr., zona } \\
\text { de abscisão } \\
\text { oblonga }\end{array}$ & $\begin{array}{l}2,5-3,2 \times 1,5-2 \mathrm{~mm} \text {, } \\
\text { elíptico, extremidades } \\
\text { obtusas }\end{array}$ & $\begin{array}{l}0,8-1,2 \times 0,8-1,1 \mathrm{~mm}, \\
\text { arredondado }\end{array}$ \\
\hline S. schlechtendaliana & $\begin{array}{l}\text { 3,5-4,4 mm compr., } \\
\text { ápice agudo, densamente } \\
\text { papiloso, papilas } \\
\text { lanceoladas à triangulares }\end{array}$ & $\begin{array}{l}0,8-1 \mathrm{~mm} \\
\text { compr., zona } \\
\text { de abscisão } \\
\text { elíptica }\end{array}$ & $\begin{array}{l}2-2,7 \times 1,5-1,8 \mathrm{~mm} \text {, } \\
\text { rômbico-elíptico, } \\
\text { extremidades agudas }\end{array}$ & $\begin{array}{l}0,8-1 \times 0,7-1 \mathrm{~mm}, \\
\text { arredondado }\end{array}$ \\
\hline S. tetraptera & $\begin{array}{l}2,2-3,5 \mathrm{~mm} \text { compr., } \\
\text { ápice agudo, densamente } \\
\text { papiloso, papilas } \\
\text { triangulares }\end{array}$ & $\begin{array}{l}\text { 1,2-2 mm } \\
\text { compr., zona } \\
\text { de abscisão } \\
\text { elíptica }\end{array}$ & $\begin{array}{l}3-3,7 \times 1,8-2 \mathrm{~mm} \text {, } \\
\text { elíptico, extremidades } \\
\text { emarginadas }\end{array}$ & $\begin{array}{l}1-1,2 \times 0,8-1 \mathrm{~mm}, \\
\text { arredondado }\end{array}$ \\
\hline
\end{tabular}


e forma do estigma, e forma da zona de abscisão do metaestilete são apontados pela primeira vez como relevantes taxonomicamente. Apesar do pequeno número de espécies estudadas no presente trabalho, acreditamos que esses caracteres também se mostrarão relevantes quando analisados num contexto mais amplo no conjunto de espécies do gênero. Destacamos também como relevantes para a sistemática do gênero, as seguintes características do carpoatlas: dimensões, forma, principalmente a apresentada pelas extremidades, e o forame. Além de relevantes taxonomicamente, os caracteres carpológicos são de fácil observação tanto em materiais frescos quanto em materiais de herbário.

Tratamento taxonômico

Loganiaceae R.Br. ex Mart., Nov. Gen. Sp. Pl. 2: 133. 1827, nom. cons.

Arbustos, lianas, subarbustos ou ervas. Raízes fibrosas. Caule cilíndrico a quadrangular, liso a estriado, lenticelas orbiculares ou elípticas presentes ou não, glabro, glabrescente a pubescente, inermes ou com espinhos simples, geralmente opostos às folhas; gavinhas quando presentes opostas às folhas. Folhas opostasdísticas ou cruzadas, ás vezes verticiladas no ápice dos ramos, pecioladas; estípulas interpeciolares ou epipeciolares, lineares ou triangulares, caducas ou persistentes; lâmina inteira, nervação broquidódroma, acródromo-broquidódroma, imperfeito-basal ou supra-basal, margem glabra. Inflorescência terminal e/ou axilar, solitária ou agrupadas, composta por cimeiras escorpioides, corimboides ou aparentemente racemosas, raro reduzidas a flores solitárias. Flores actinomorfas, perfumadas ou inodoras, sésseis, subsésseis, pediceladas; cálice com (4-)5-(6) lacínios, variavelmente conato, corola com (4-)5-(6) lobos, campanulada, rotácea ou hipocrateriforme, prefloração valvar; estames (4-)5-(6), epipétalos, inseridos na fauce da corola, livres entre si, anteras glabras a pubescentes, rimosas; ovário súpero, bicarpelar, bilocular, lóculos uni ou multiovulados, estilete terminal, filiforme, estigma simples, capitado ou bilobado, papiloso. Frutos bagas ou cápsulas septicida-loculicida. Sementes 1-várias por lóculo, achatadas ou não, oblongas a reniformes a disciformes a globosas, testa verrucosa ou reticulada.

\section{Chave dos gêneros de Loganiaceae}

1. Ervas a subarbustos, sem gavinhas e/ou espinhos; inflorescências compostas por cimeiras escorpioides; estilete articulado; fruto cápsula 1. Spigelia

1'. Lianas ou arbustos, raramente árvores, frequentemente com gavinhas e/ou espinhos; inflorescências compostas por cimeiras corimboides ou aparentemente racemosas; estile não-articulado; fruto baga..

2. Strychnos

1. Spigelia L., Sp. Pl. 1: 149. 1753. Tipo: Spigelia anthelmia $\mathrm{L}$.

Ervas a subarbustos. Caule cilíndrico a quadrangular, liso a estriado, com ou sem alas, inermes, sem gavinhas. Estípulas interpeciolares, glabras ou pilosas, margem plana glabra ou ciliada. Folhas opostas-dísticas ou cruzadas, ás vezes verticiladas no ápice dos ramos, sésseis, subsésseis, pecioladas, nervação broquidódroma, margem plana ou revoluta, glabra ou ciliada ou papiloso-ciliada. Inflorescência terminal e/ ou axilar, solitária ou agrupada, composta por uma cimeira escorpioide, raro reduzida a flores solitária. Flores inodoras, pentâmeras, sésseis a subsésseis; cálice persistente, variavelmente conato, corola tubular, infundibuliforme, internamente com ou sem estrias longitudinais, lobos elípticos a lanceolados a triangulares; estames inclusos, anteras glabras, lineares a oblongas a ovadas, base sagitada ou cordada, ápice agudo a mucronado ou obtuso a emarginado; ovário oblongo a globoso, 2-locular, multiovulado, estilete terminal, articulado, filiforme, estigma papiloso. Fruto cápsula septicida-loculicida, lateralmente comprimida, com uma parte basal (carpoatlas) que permanece unida ao pedúnculo, endurecida e espessada, com forame na porção central, estilete persistente (metaestilete) inteiro, cilíndrico, com zona de abscisão elíptica ou oblonga ou arredondada. Sementes 1-várias por lóculo, reunidas formando uma massa arredondada, achatadas ou não, oblongas a reniformes a disciformes a globosas, testa verrucosa ou reticulada. 


\section{Chave de identificação das espécies de Spigelia ocorrentes no estado do Rio de Janeiro}

1. Caule quadrangular ao menos na região apical; lacínios do cálice $0,5-2 \mathrm{~mm}$ compr., livres até $1 / 2$ do compr., raro livres até $4 / 5$ do compr..

2. Folhas opostas, lâminas com nervuras pouco visíveis, planas, margens revolutas, estípulas lineares; inflorescências com eixo cilíndrico, irregularmente espessado; anteras lineares, ápice do estigma obtuso; metaestilete maior que $2 \mathrm{~mm}$ compr., forame elíptico (Figs. 3; 8c).

1.3. Spigelia laurina

2'. Folhas verticiladas no ápice dos ramos, lâminas com nervuras bem marcadas, buladas, margens planas, estípulas triangulares; inflorescência com eixo quadrangular, fino; anteras oblongas a ovadas, ápice do estigma agudo; metaestilete até 1,5 mm compr., forame arredondado ............. 3

3. Folhas com margens ciliado-papilosas; inflorescências agrupadas; corola internamente com estrias róseas a arroxeadas; carpoatlas rômbico-elíptico, extremidades agudas (Fig. 8h) ......

1.8. Spigelia schlechtendaliana

3'. Folhas com margens glabras ou ciliadas; inflorescência solitária; corola internamente sem estrias; carpoatlas elíptico, extremidades obtusas ou emarginadas.

4. Caule com alas inconspícuas em direção aos nós; botões $0,8-1 \mathrm{~cm}$ compr.; zona de abscisão do metaestilete oblonga, carpoatlas com extremidades obtusas (Figs. 6; 8g)..

1.7. Spigelia scabra

4'. Caule com alas evidentes em direção aos nós; botões 1,4-1,8 cm compr.; zona de abscisão do metaestilete elíptica, carpoatlas com extremidades emarginadas (Figs. 7; 8i).

1.9. Spigelia tetraptera

1'. Caule cilíndrico; lacínios do cálice 2,5-6 mm comp., livres até 3/4 do compr.

.5

5. Inflorescências agrupadas, raro solitária; anteras maiores que 1,6 $\mathrm{mm}$ compr.; sementes até 3 por lóculo.

6. Folhas pecioladas, pecíolos 3-8 mm compr., lâminas com base simétrica, cuneada, margem plana; flores subsésseis, pedicelo ca. $2 \mathrm{~mm}$ compr., lacínios do cálice eretos, anteras com o ápice agudo; estigma 0,8-1,3 mm compr.; carpoatlas largo rômbico-elíptico (Figs. 4; 8d) ...

1.4. Spigelia macrophylla

6'. Folhas sésseis ou pecíolos ca. 0,3-0,5 mm compr., lâminas com base assimétrica, truncada a arredondada, margem revoluta; flores sésseis, lacínios do cálice reflexos, anteras com o ápice obtuso a emarginado, estigma 2-2,8 mm compr.; carpoatlas rômbico-elíptico (Fig. 8f) ........ 1.6. Spigelia reflexicalyx

5'. Inflorescência solitária; anteras até 1,5 mm compr.; sementes mais que 3 por lóculo, raro 3 ou menos

7. Folhas opostas; eixo das inflorescências inconspícuos; flores sésseis, corola internamente sem estrias; fruto piloso, carpoatlas com extremidades emarginadas (Figs. 5; 8e)

1.5. Spigelia pusilla

7'. Folhas verticiladas no ápice dos ramos; eixo das inflorescências alongados, maiores ou iguais a $0,5 \mathrm{~mm}$ compr.; flores subsésseis, pedicelos maiores ou iguais a $0,5 \mathrm{~mm}$ compr., corola internamente com estrias róseas a arroxeadas; fruto glabro, carpoatlas com extremidades agudas ou obtusas.

8. Pecíolos achatados a cilíndricos, glabros; inflorescências 3-9-flora, eixo das inflorescências sinuoso, irregularmente espessado; anteras com base sagitada, ápice do estigma obtuso; metaestilete 2,5-4 mm compr., zona de abscisão arredondada, carpoatlas elíptico; sementes amarelas (Figs. 1; 2; 8a).... 1.1. Spigelia beyrichiana

8'. Pecíolos canaliculados, pubescentes a glabrescentes; inflorescências 12-43-flora, eixo das inflorescências reto, delicado; anteras com base cordada, ápice do estigma agudo; metaestilete 1-2,2 mm compr., zona de abscisão elíptica, carpoatlas rômbico-elíptico; sementes nigrescentes (Fig. 8b) 1.2. Spigelia flemmingiana 
1.1. Spigelia beyrichiana Cham. \& Schltdl., Linnaea 1(2): 203. 1826.

Figs. 1;2; $8 \mathrm{a}$

Erva ou subarbusto ca. $15-50 \mathrm{~cm}$ alt. Caule liso ou estriado, cilíndrico, sem alas, glabro. Estípulas triangulares, glabras, margem glabra. Folhas opostas-dísticas ou cruzadas, verticiladas no ápice dos ramos, pecioladas; pecíolo 0,3-2,2 $\mathrm{cm}$ compr., decurrente, achatado a cilíndrico, glabro; lâmina 2,6-10 × 1-3,5 cm, discolor, elíptica a oblonga, membranácea, plana, nervuras visíveis, glabra em ambas as faces, ou face abaxial glandulosa, base simétrica, cuneada, margem plana, glabra, às vezes ciliada, ápice agudo a acuminado. Inflorescência terminal, solitária, 3-9-floras, eixo maior ou igual a $0,5 \mathrm{~mm}$ compr., sinuoso, cilíndrico, irregularmente espessado. Flores subsésseis, pedicelos ca. 4,5 mm compr.; botões ca. 1-1,7 cm compr.; cálice com lacínios ca. $5 \mathrm{~mm}$ compr., eretos, lanceolados a ovado-lanceoladas, livres até $3 / 4$ do compr., glabros em ambas as faces, margem glabra, ápice agudo a acuminado; corola alva a alvo-rósea, internamente com estrias róseas a arroxeadas, lobos 1,4-1,8 cm compr., glabros, alvos a alvo-róseos; anteras ca. 1,5 mm compr., lineares, base sagitada, ápice agudo a levemente mucronado; ovário 2-2,5 × 1,8-2 mm, ovado a globoso, glabro, estilete 3-3,6 mm compr., estigma ca. 4-4,3 $\mathrm{mm}$ de compr., ápice obtuso, levemente papiloso, papilas triangulares. Cápsulas 3-6,2 mm diâm., castanhas, obcordadas, glabras, metaestilete $2,5-4 \mathrm{~mm}$ compr., zona de abscisão arredondada; pericarpo ca. 0,25 $\mathrm{mm}$ espessura, epicarpo liso, glabro, verde ou castanho; mesocarpo rígido, cartáceo, endocarpo brilhante, marfim; carpoatlas 3,5-8 $\times$ 2,5-6,4 mm, elíptico, extremidades obtusas; forame arredondado, 1,5-1,7 × 1,4-1,5 mm. Sementes até 11 por lóculo, 1,3-2 mm diâm., amarelas quando secas, reniformes a oblongas, achatadas, glabras. Material examinado: Angra dos Reis, cachoeira da praia do Manduri, 17.XI.1993, fl. e fr., D.A. Santin et al. 29941 (UEC). Cachoeiras de Macacu, Japuíba, 17.IV.1926, fl., F.C. Hoehne \& A. Gehrt (SP 17401). Duque de Caxias, Xerém, 22.III.1950, fl., A.C. Brade 20269 (RB). Guapimirim, Granja Monte Olivete, margem do rio Bananal, 20.X.1994, fl. e fr., J.M.A. Braga et al. 1432 (RB). Magé, próximo ao CPRJ, 21.X.1983, fl., T.H. Alcântara \& R.F. Oliveira 204 (UB). Nova Friburgo, Macaé de Cima, Fazenda do Sr. Manoel Lobão, 27.XI.1986, fl. e fr., J.F.A. Baumgratz 379 (RB). Paraty, Rio Corisco, 29.VI.1993, fl. e fr., T. Konno et al. 172 (RB). Petrópolis, Serra da estrela, s.d., fl., L. Riedel 581 (NY). Rio de Janeiro 27.IV.1958, fr., J.A. Costa. et al. 14 (R). Santa Maria Madalena, 19.V.1994, fl., R. Marquete 2036 (RB). Serra dos Órgãos 1833, M. Vauthier 170 (G); 1838, fl., G. Gardner 724 (G).
Espécie nativa do Brasil, que habita a Caatinga, Cerrado e Floresta Atlântica. Está distribuída pelos estados da Bahia, Minas Gerais, Espírito Santo, Rio de Janeiro, São Paulo, Santa Catarina, Paraná e Rio Grande do Sul (BFG 2015). No estado do Rio de Janeiro ocorre nos municípios de Angra dos Reis, Cachoeiras de Macacu, Duque de Caxias, Guapimirim, Magé, Nova Friburgo, Paraty, Petrópolis e Santa Maria Madalena (Fig. 9). Spigelia beyrichiana se caracteriza pelas folhas discolores, e flores alvas a alvo-róseas, e face interna da corola provida de estrias róseas a arroxeadas (Figs. 1;2). Comumente heliófila, mas também se desenvolve em locais sombrios, em solo argiloso, geralmente úmido. Floresce e frutifica durante o ano todo.

1.2. Spigelia flemmingiana Cham. \& Schltdl., Linnaea 1(2): 203. 1826.

Fig. $8 \mathrm{~b}$ = Spigelia anthelmia auct. non L. (1753) in Vellozo, Fl. flum.: 95. 1829. \& Fl. flum. Icon. 2: t. 145.1831.

Erva a subarbusto ca. 0,4-1,5 m alt. Caule estriado, cilíndrico, sem alas, glabro. Estípulas triangulares, glabras, margem ciliadas. Folhas opostas-dísticas, verticiladas no ápice dos ramos, pecioladas; pecíolo 1-3 cm compr., decurrente, canaliculado, pubescente a glabrescente; lâmina 5,6-8,6 × 1,5-3 cm, discolor, elíptica a lanceolada, plana, membranácea, nervuras visíveis, face adaxial glabrescente, abaxial glabra, eglandular, base simétrica, obtusa a cuneada, margem plana, ciliada, ápice agudo. Inflorescência terminal, solitária, 12-43-floras, eixo maior ou igual a $0,5 \mathrm{~mm}$ compr., reto, cilíndrico, delicado. Flores subsésseis, pedicelos ca. $2 \mathrm{~mm}$ compr.; botões ca. 1,4 cm compr.; cálice com lacínios 2,5-4 $\mathrm{mm}$ compr., eretos, lanceolados, livres até $3 / 4$ do compr., margem ciliada, ápice agudo a atenuado; corola alva a rósea, internamente com estrias róseas a arroxeadas, lobos ca. $8 \mathrm{~mm}$ compr., glabros, alvos a róseos a arroxeados; anteras ca. 1,4 mm compr., lineares, base cordada, ápice agudo; ovário $0,7-1 \times 0,5-0,6 \mathrm{~mm}$, oblongo, glabro, estilete ca. $1-2,1 \mathrm{~mm}$ compr., estigma $2-2,5 \mathrm{~mm}$ compr., lanceolado, ápice levemente agudo, densamente papiloso, papilas lanceoladas, agudas. Cápsulas 2,8-4 × 3,7-4,8 mm, depresso-obcordadas, glabras, metaestilete $1-2,2 \mathrm{~mm}$ compr., zona de abscisão elíptica; pericarpo ca. $0,25 \mathrm{~mm}$ de espessura, epicarpo gelatinoso, glabro, castanho, mesocarpo rígido, cartáceo, endocarpo brilhante, marfim; carpoatlas 1,8-2 × 1-1,4 mm, rômbico-elíptico, 


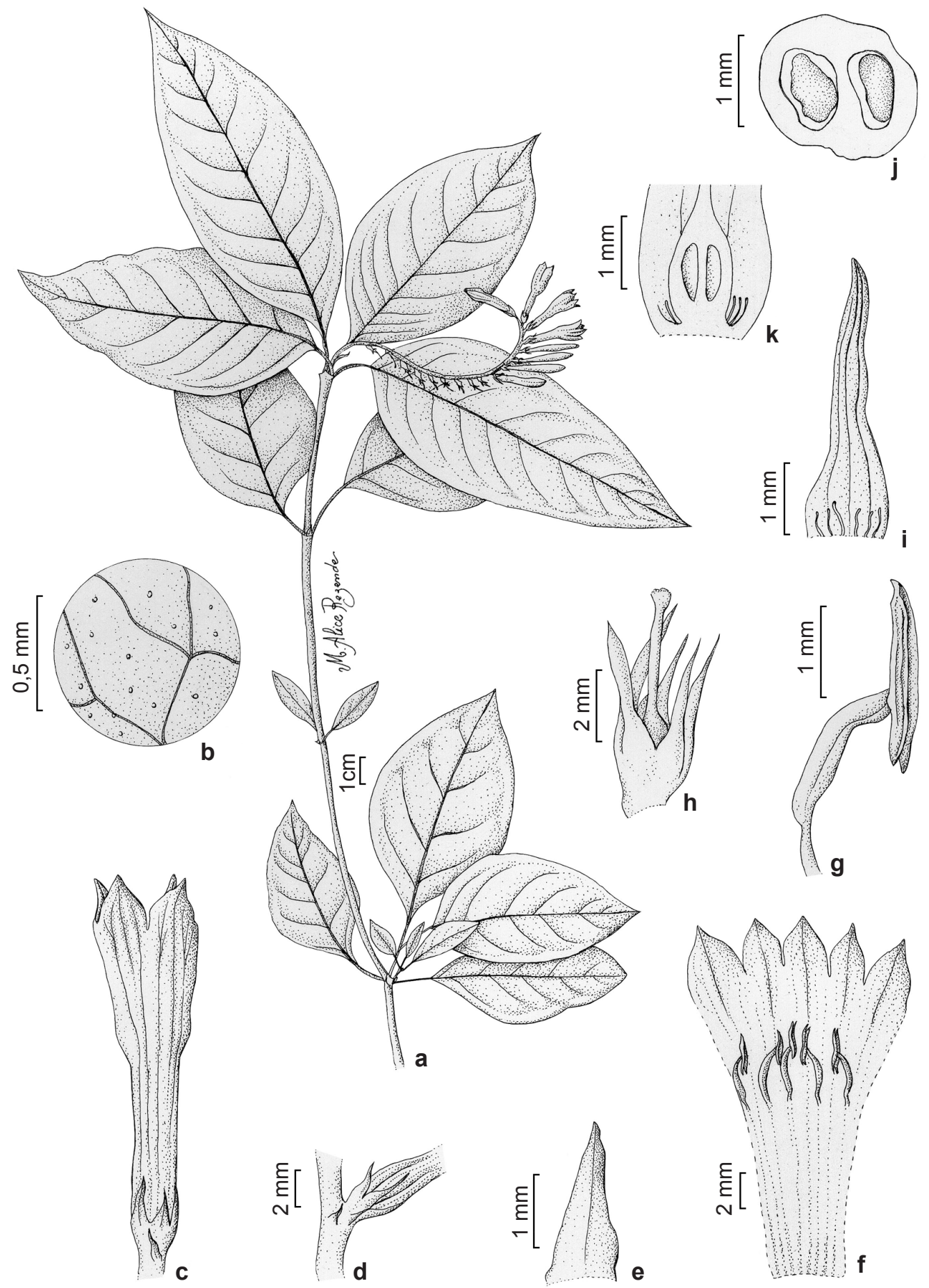

Figura 1 - Spigelia beyrichiana - a. ramo florífero; b. detalhe da lâmina foliar com face abaxial glandulosa; c. flor; d. detalhe do cálice; e. detalhe da face adaxial do lacínio do cálice; f. corola aberta mostrando os estames; g. detalhe do estame; $h$. detalhe do cálice e do gineceu, evidenciando estilete e estigma; i. detalhe da face abaxial do lacínio do cálice; j,k. ovário, seção longitudinal e transversal, respectivamente. Ilustrações: M.A. Rezende, baseadas em J.F.A. Baumgratz 379 (RB).

Figure 1 - Spigelia beyrichiana Cham. \& Schltdl. - a. flowering branch; b. detail of the leaf blade with abaxial glandulous surface; c. flower; d. detail of the calyx; e. detail of the adaxial surface of the calyx lobe; f. open corolla showing the stamens; g. detail of the stamens; h. detail of the calyx and of the gynoecium, showing syle and stigma; i. detail of the abaxial surface of the calyx lobe; j,k. ovary, longitudinal and cross section, respectively. Illustrations: M.A. Rezende, based on J.F.A. Baumgratz 379 (RB). 
extremidades agudas; forame elíptico, 0,7-0,9 $\times$ 0,25-0,3 mm. Sementes 3 por lóculo, 1-1,5 mm compr., nigrescentes, oblongas, reniforme, raro globosas, glabras.

Material examinado: Niterói, Engenho do Mato, Rua 31 , quadra 45 , lote 2, 3.V.2011, fl. e fr., A.A.M. de Barros 4260 (RB, RFFP). Nova Friburgo, Alto Macaé, 12.III.1870, fl. e fr., A. Glaziou 4026 (R). Paraty, Ponta Negra, Praia dos Antigos, 13.IV.1994, fr., R. Marquete 1599 (RB); Laranjeiras, caminho para a Praia do Sono, APA Cairuçu, 12.V.1994, fl. e fr., R. Reis 110 (HUEFS, RB); loc. cit., Parati-Mirim, estrada para Parati-Mirim, mata de restinga próximo de mangue, 8.VII.2008, fl. e fr., N. Marquete 623 (RB). Silva Jardim, Reserva Biológica Poço das Antas, estrada para a casa do Aristides, caminho que vai para o rio Aldeia, 26.I.1995, fl. e fr., J.M.A. Braga et al. 1865 (RB). S.loc., 1814-1831, F. Sellow (BR 5179398).

Espécie nativa do Brasil, que habita o Cerrado e a Floresta Atlântica. Ocorre nos estados de Pernambuco, Sergipe, Bahia, Minas Gerais, Espírito Santo, Rio de Janeiro, São Paulo, Santa Catarina, Paraná e Rio Grande do Sul (BFG 2015). No estado do Rio de Janeiro ocorre nos municípios de Niterói, Nova Friburgo, Paraty e Silva Jardim (Fig. 9). Spigelia flemmingiana se caracteriza pelas folhas discolores e flores alva a róseas a arroxeadas, internamente com listras róseas. É uma espécie característica de sub-bosques de mata de encosta em altitude entre 20-1000 m.s.m. Coletada com flores durante o ano todo e em frutos entre janeiro e julho. Vellozo $(1829,1831)$ aplicou erroneamente o nome $S$. anthelmia L. descrita em seu trabalho. A planta ilustrada na Flora fluminensis na verdade corresponde a S. flemmingiana.
1.3. Spigelia laurina Cham. \& Schltdl. Linnaea 1(2): 204. 1826.

Figs. 3; 8c

Erva a subarbusto ca. $30-60 \mathrm{~cm}$ alt. Caule estriado, cilíndrico, quadrangular ao menos na região apical, sem alas, glabro. Estípulas lineares, glabras, margem glabra. Folhas opostas-dísticas ou cruzadas, subsésseis a pecioladas; pecíolo 2-4 mm compr., decurrente, cilíndrico, glabro; lâmina 3,9-19 × 0,5-3,6 cm, elíptica ou lanceolada, membranácea, plana, nervuras pouco visíveis, glabra, base simétrica, cuneada a obtusa, margem revoluta, glabra, ápice agudo a acuminado. Inflorescências terminais, agrupadas, 5-9-floras, eixo maior ou igual a $0,5 \mathrm{~mm}$ compr., sinuoso, cilíndrico, irregularmente espessado. Flores subsésseis, pedicelo ca. 1,4 mm compr.; botões ca. 0,9-1,5 cm compr.; cálice com lacínios ca. $2 \mathrm{~mm}$ compr., eretos, lanceolados a ovado-lanceolados, livres até 4/5 do compr., glabros, margem ciliada, ápice agudo; corola alva a rósea, internamente sem estrias, lobos 0,5-1,8 cm compr., glabros, róseos a arroxeados; anteras 1-1,4 mm compr., lineares, base cordada, ápice agudo; ovário 0,8-1,3 × 0,6 $\mathrm{mm}$, oblongo, glabro, estilete ca. 2,5-3,2 mm compr., estigma 4-4,5 mm compr., obtuso no ápice, levemente papiloso, papilas triangulares. Cápsulas 4-4,8 $\times 5-5,6 \mathrm{~mm}$, obcordadas, glabras, metaestilete ca. 0,8-1 cm compr., zona de abscisão elíptica; pericarpo ca. $0,25 \mathrm{~mm}$ de espessura, epicarpo gelatinoso, glabro, castanho; mesocarpo rígido, cartáceo, endocarpo brilhante, marfim; carpoatlas 3,5-4 × 2-2,2 mm, elíptico, extremidades obtusas a truncadas, forame elíptico, 0,9-1 × 0,8-1 $\mathrm{mm}$. Sementes 2 por lóculo, ca. $3 \mathrm{~mm}$ diâm., castanha
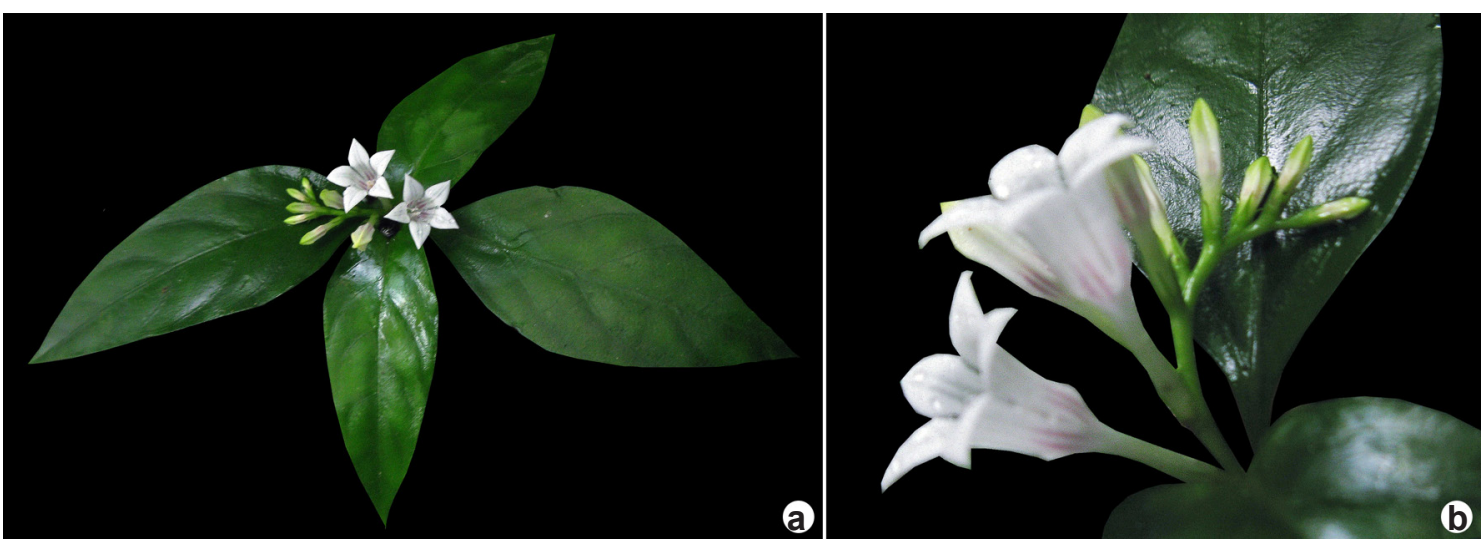

Figura 2 - Spigelia beyrichiana Cham. \& Schltdl. - a. ramo florífero; b. detalhe da inflorescência, mostrando o eixo sinuoso e irregularmente espessado. Fotos: I.G. Costa.

Figure 2 - Spigelia beyrichiana Cham. \& Schltdl. - a. flowering branch; b. detail of the inflorescence, showing the sinuate and irregularly thickened axis. Photos: I.G. Costa. 

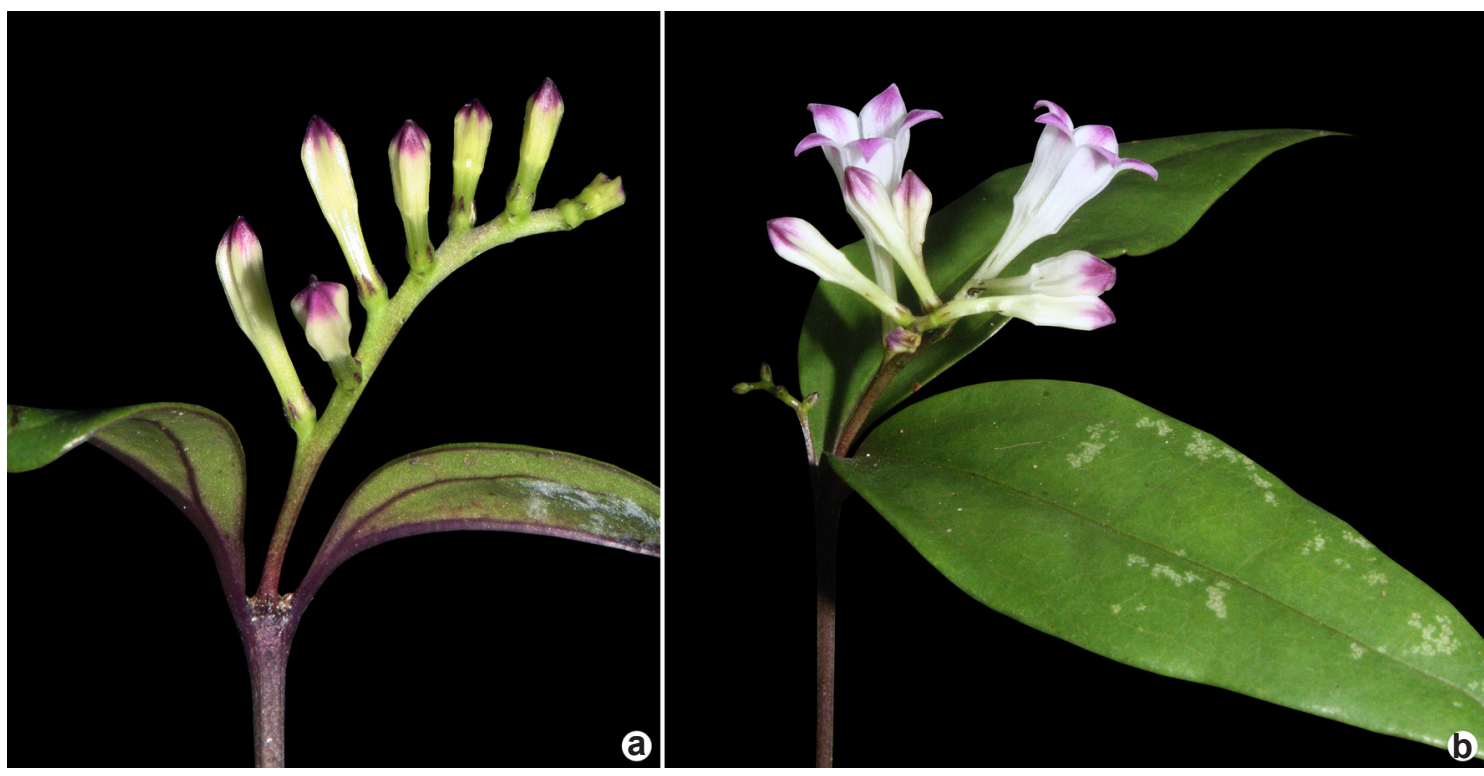

Figura 3 - Spigelia laurina Cham. \& Schltdl. - a. detalhe da inflorescência, mostrando as flores subsésseis, o cálice e os botões florais; b. detalhe da inflorescência, mostrando as flores em antese. Fotos: M.O.O. Pellegrini.

Figure 3 - Spigelia laurina Cham. \& Schltdl.: a. detail of the inflorescence, showing the subsessile flowers, calyx and flower buds; b. detail of the inflorescence, showing the flowers at anthesis. Photos: M.O.O. Pellegrini.

ou nigrescentes, arredondadas a oblongas, glabras. Material examinado: Itatiaia, IX.1934, fl., A.C. Brade 13997 (RB). Petrópolis, s.loc., XI.1944, fl., O.C. Goés \& E. Dionísio 1187 (RB). Rio de Janeiro, Barra da Tijuca, 28.X.1938, fl., F. Markgraf 3090 (RB); 22.VIII.1932, fl. e fr., J.G. Kuhlmann (RB 137542). Teresópolis, Serra dos Órgãos, 26.X.1949, fl., E. Pereira 627 (RB). S.loc., X.1825, fr., S. Riedel 426 (RB).

Espécie endêmica do Brasil, registrada para os estados da Bahia, Espírito Santo e Rio de Janeiro (BFG 2015). Endêmica da Floresta Atlântica, onde habita a Floresta Ombrófila Densa, Floresta Ombrófila de Baixada, e a Restinga. Pode ser encontrada em ambientes sombrios e áreas abertas, crescendo em solo humoso ou sílico-argiloso em altitudes que variam de 10-800 m.s.m. No estado do Rio de Janeiro ocorre nos municípios de Itatiaia, Petrópolis, Rio de Janeiro e Teresópolis (Fig. 9). Possui flores alvas, róseas a arroxeadas, sem estrias na face interna da corola (Fig. 3), e geralmente floresce o ano todo com frutos de fevereiro a julho.

\subsection{Spigelia macrophylla (Pohl) A. DC. Prodr. 9:} 8. 1845 .

Figs. 4; 8d

Erva ca. 20-35 cm alt. Caule liso, pouco estriado, cilíndrico, sem alas, pubescente à glabrescente. Estípulas triangulares, glabras, margem glabra. Folhas opostas-dísticas ou cruzadas, pecioladas; pecíolo 3-8 $\mathrm{mm}$ compr., decurrente, cilíndrico, pubescente; lâmina 8,7-16 $\times$ 4,1-6,6 cm; discolor, elíptica, membranácea, planas, nervuras visíveis, glabra a esparsamente pilosa na face adaxial, esparsamente pilosa na face abaxial, base simétrica, cuneada, margem ciliada, ápice agudo a acuminado. Inflorescências terminais, agrupadas, raro solitária, 8-16-floras, eixo maior ou igual a 0,5 mm compr., reto, cilíndrico, delicado. Flores subsésseis, pedicelo ca. 2 mm compr.; botões ca. 1,1 cm compr.; cálice com lacínios 3-6 mm compr., eretos, ovados, ápice agudo, livres até 3/4 do compr., glabros em ambas as faces, margem ciliada; corola alva a rósea, internamente com estrias róseas a arroxeadas, lobos 1,6-1,8 cm compr., glabros, róseos; anteras 1,5-1,8 mm compr., ovadas, base sagitada, ápice agudo; ovário $1-2,4 \times 1-2 \mathrm{~mm}$, ovado à globoso, glabro, estilete 2-2,8 mm compr., estigma 0,8-1,3 mm compr., lanceolado no ápice, papiloso, papilas triangulares. Cápsulas 3-4,1 × 2,1-3,3 mm, obcordadas, glabras, metaestilete 0,8-2 mm compr., zona de abscisão elíptica; pericarpo ca. 0,05 mm espessura, epicarpo liso, glabro, castanho, mesocarpo rígido, cartáceo, endocarpo brilhante, castanho; carpoatlas 2,5-3,2 $\times 1,8-2 \mathrm{~mm}$, largo rômbico-elíptico, extremidades agudas; forame arredondado, $1 \times 0,9-1 \mathrm{~mm}$. Sementes 2-3 por lóculo, ca. 1,5 mm diâm., acastanhadas, oblongas, glabras. 


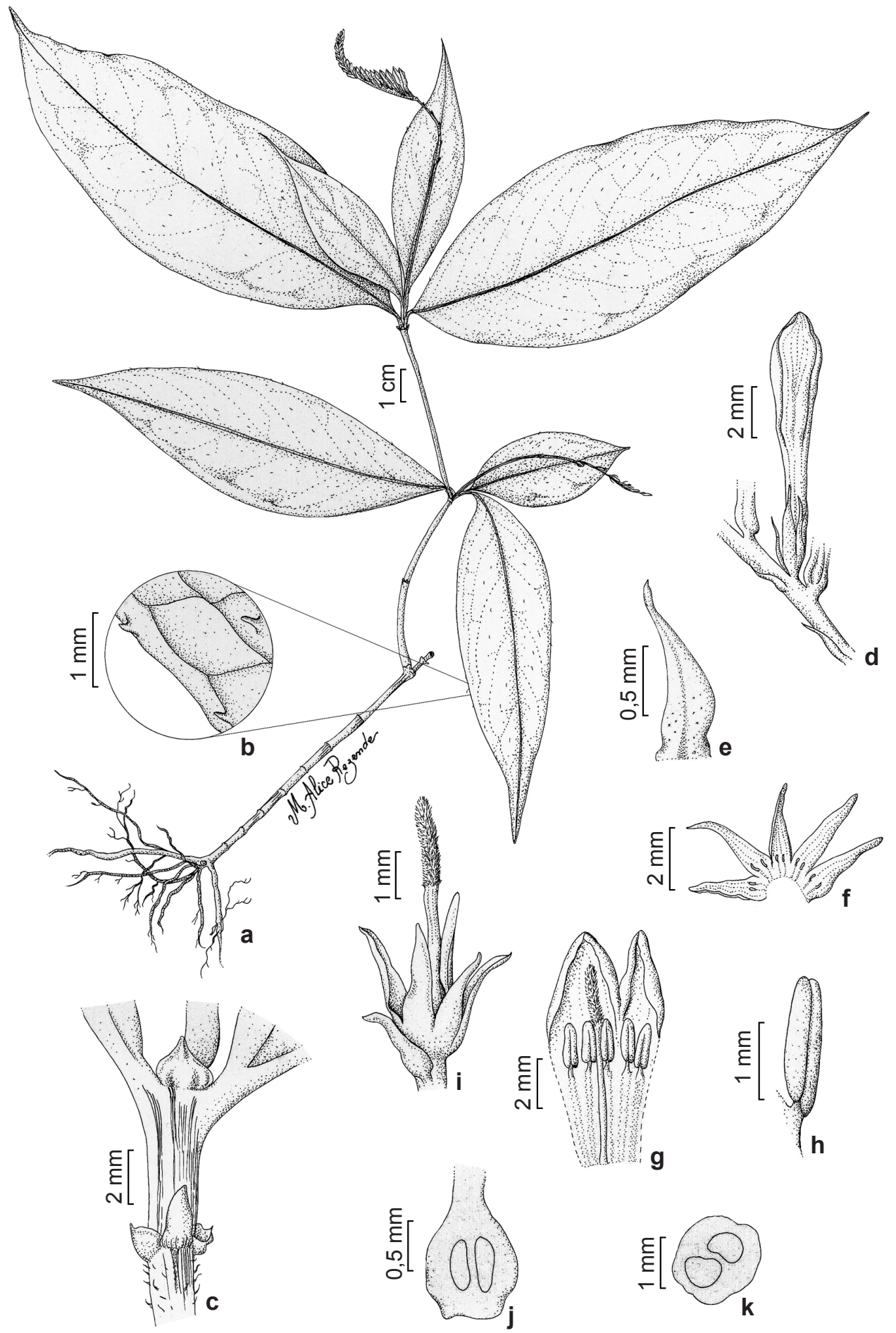

Figura 4 - Spigelia macrophylla - a. ramo florífero; b. detalhe da lâmina foliar; c. detalhe do ramo e das estípulas; d. botão floral; e. detalhe da lacínio lanceolada, face adaxial; f. corola aberta mostrando os estames; g. detalhe dos estames e do estigma papiloso; h. antera; i. detalhe do cálice e do gineceu; j,k. ovário, secção longitudinal e transversal, respectivamente. Ilustrações: M.A. Rezende, baseadas em R. Marquete 1397 (RB).

Figure 4 - Spigelia macrophylla - a. flowering branch; b. detail of the leaf blade; c. detail of the branch and stipules; d. flower bud; e. detail of the adaxial surface of the calyx lobe; f. open corolla showing the stamens; g. detail of the stamens and of the papillose stigma; $h$. anther; i. detail of the calyx and of the gynoecium; j,k. ovary, longitudinal and cross section, respectively. Illustrations: M.A. Rezende, based on R. Marquete 1397 (RB). 
Material examinado: Mangaratiba, Reserva Ecológica do Rio das Pedras, trilha das Borboletas, 1.XII.1996, fl. e fr., J.M.A. Braga et al. 3687 (RB); proximidades do Poço do Rio Grande, 25.I.1998, fr., J.M.A. Braga et al. 4749 (RB). Paraty, APA Cairuçu, Laranjeiras, Cachoeira das Pedras, caminho para a Praia do Sono, 8.XII.1993, fl., R. Marquete 1397 (RB). Petrópolis, Serra da Estrela, 23. XII.1882, fl., A. Glaziou 1499 (R); 28.VII.1929, fl. e fr., A.C. Brade 10459 (R). Rio de Janeiro, Jacarepaguá, Represa Camorim, s.d., fr., J.G. Kuhlmann (RB 148734); Praia de Guaratiba, 5.I.1934, fl., A. Sampaio et al. (R 94537). Santa Maria Madalena, Santo Antônio do Imbé, Furquilhas, IV.1932, fl., A.C. Brade \& Santos Lima 11721 (R).

Espécie endêmica do Brasil, ocorrendo nos estados do Espírito Santo, Rio de Janeiro e São Paulo (BFG 2015). É restrita a Floresta Atlântica e habita a floresta ombrófila, ocorrendo em relevos íngremes. No estado do Rio de Janeiro ocorre nos municípios de Mangaratiba, Paraty, Petrópolis, Rio de Janeiro e Santa Maria Madalena (Fig. 10). Apresenta corola alva a rósea, e como informa o epiteto específico, apresenta as maiores folhas entre as espécies deste estudo (Fig. 4). Floresce durante todo o ano. Coletada com fruto em janeiro, julho e agosto.

1.5. Spigelia pusilla Mart., Nov. Gen. Sp. Pl. 2: 130. 1826.

Figs. 5; 8e

Erva ca. $15-40 \mathrm{~cm}$ alt.; caule liso, cilíndrico, sem alas, piloso a esparsamente piloso. Estípulas triangulares, tomentosas na face abaxial, margem tomentosa. Folhas opostas-dísticas, cruzadas no ápice, subsésseis; pecíolo 0,5-3 mm compr., decurrente, cilíndrico, pubescente; lâmina 0,6-(1,8-)3,6 × 0,5-2,8 cm, elíptica, ovada a lanceolada a espatulada, membranácea, plana, nervuras visíveis, face adaxial esparso-pubescente, abaxial esparso-pubescente a tomentosa, base simétrica, cuneada, margem plana, ciliada, ápice agudo. Inflorescência terminal e axilar, solitária, 1-3-floras, eixo inconspícuo. Flores sésseis; botões ca. 5,5 mm compr.; cálice com lacínios ca. 3,5 mm compr., eretos, linear-lanceolados, esparsamente pubescentes, margem ciliada, ápice agudo a acuminado, livres até 3/4 do compr.; corola alva a rósea, internamente sem estrias, lobos 9-9,5 mm compr., glabros, alvos a alvo-róseos; anteras ca. $1 \mathrm{~mm}$ compr., ovadas, base sagitada, ápice acuminado; ovário 0,4-1,2 mm diâm., globoso, glabrescente ou esparso-pubescente, estilete ca. 2-2,8 mm compr.; estigma 2,2-3 mm compr., lanceolado, ápice agudo, densamente papiloso, papilas lanceoladas. Cápsulas 2,8-3 × 4,5-5 mm, obcordadas, pilosas, metaestilete ca. 1-1,2 mm compr., zona de abscisão elíptica, pericarpo ca. 0,2 mm de espessura, epicarpo pubescente apenas da porção mediana ao ápice, mesocarpo rígido, cartáceo, endocarpo acetinado, pardo; carpoatlas 3,6-4 × 1,4-1,6 mm, elíptico, extremidades
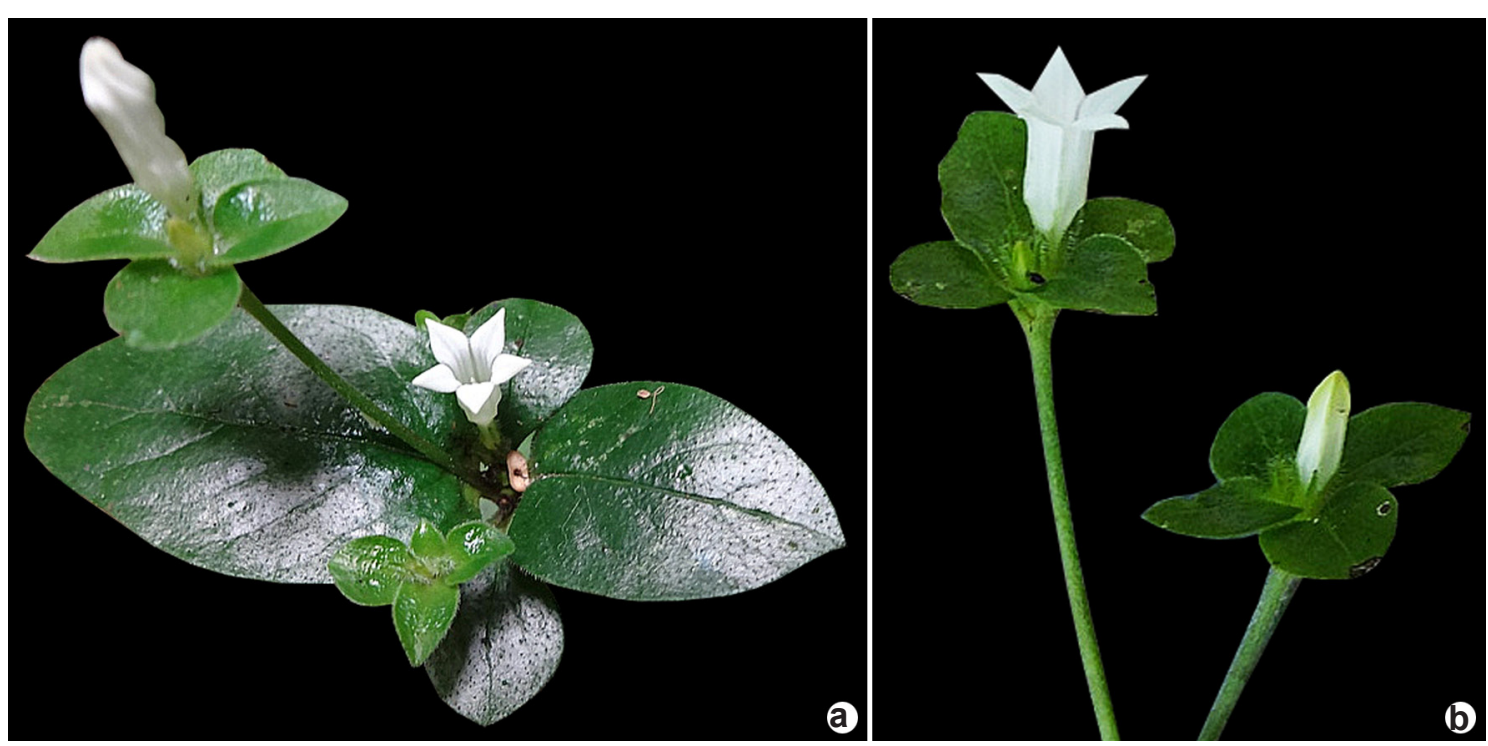

Figura 5 - Spigelia pusilla - a. hábito com botões e flor em antese; b. ramo com botões jovens e flor em antese. Fotos: P. Schwirkowski.

Figure 5 - Spigelia pusilla - a. habit with flower buds and open flower; b. branch with young flower buds and open flower. Photos: P. Schwirkowski. 
emarginadas, forame arredondado, 0,5-0,6 $\times$ 0,5-0,6 mm. Sementes oblongas, glabras, 2-8 por lóculo, ca. $3 \mathrm{~mm}$ diâm., amareladas quando jovens e nigrescentes quando maduras.

Material examinado: Rio de Janeiro, Jardim Botânico do Rio de Janeiro, II.1910, fl., A. Frazão 858 (RB); Gericinó, 24.V.1931, fl. e fr., A.C. Brade 10859 (R); 1933, fr., J.G. Kuhlmann (RB 48129); Floresta da Tijuca, Gruta de Paulo e Virgínia, 25.II.1972, fl., D. Sucre 8537 (RB); Vertente Norte do Parque Nacional da Tijuca, 14.IV.1972, fl., D. Sucre 8829 (RB); Andaraí, 25.IX.1939, fl., J.G. Kuhlmann (RB 40599); Restinga de Grumari, 31.VIII.1968, fl., D. Sucre 3381 \& P.I.S. Braga (RB, US, NY, GUA); Matas da Alagoinha, 17.II.1952., fl., E. Pereira 664 (RB); Corcovado, Aqueduto, s.d., s.leg. (MO 100554637, RB 60572); Parque Estadual da Pedra Branca, Pau da Fome, trilha para a Pedra Branca, acesso pelo "Caminho de Santa Bárbara", Jacarepaguá, 19.III.1994, fl e fr., J.M.A. Braga et al. 1131 (RB). Santa Maria Madalena, subida para a Pedra Dubois, 22.XI.1999, fl., D.C. Zappi et al. 363 (UEC); 9.V.2009, fl. e fr., V.C. Souza et al. 33558 (ESA, RB).

Espécie endêmica do Brasil, ocorrendo nos estados de Minas Gerais, Rio de Janeiro, São Paulo, Paraná e Santa Catarina (BFG 2015). Espécie que ocorre no sub-bosque da Floresta Ombrófila e Restinga, crescendo em encostas, próximas a córregos ou solos úmidos, sendo frequente na borda da mata. No estado do Rio de Janeiro ocorre apenas nos municípios de Rio de Janeiro e Santa Maria Madalena (Fig. 10). Spigelia pusilla distingue-se por apresentar corola alva a rósea, internamente sem estrias, estigma com papilas lanceoladas, e por possuir frutos pilosos (Fig. 5). Floresce o ano todo e coletada com frutos em março e maio.

1.6. Spigelia reflexicalyx E.F.Guim. \& Fontella, Loefgrenia, 30:1 1969.

Fig. $8 f$

Erva ca. $35-45 \mathrm{~cm}$ alt. Caule liso a levemente estriado, cilíndrico, sem alas, glabro ou pubescente. Estípulas triangulares, glabras em ambas as faces. Folhas opostas, dísticas, sésseis a subsésseis; pecíolo 0,3-0,5 mm compr., decurrente, cilíndrico, glabro; lâmina 6,5-16 × 0,8-2,6 cm, concolor, lanceolada, raro elíptica, membranácea, plana, nervura visível, face adaxial glabra, abaxial glabra ou pubescente, glandulosa ou não, base assimétrica, truncada a arredondada, margem revoluta, ciliada, ápice acuminado. Inflorescência terminal ou axilar, agrupadas, raro solitária, 13-24-floras, eixo maior ou igual a $0,5 \mathrm{~mm}$ compr., reto, cilíndrico, delicado. Flores sésseis; botões 0,7-1,4 cm compr.; cálice com lacínios 2-3,5 mm compr., reflexos, ovadooblongos, livres até $3 / 4$ do compr., pubescente a glabrescente, margem ciliada ou glabra, ápice agudo; corola alvo-esverdeada, internamente com estrias esverdeadas a arroxeadas, lobos 1,9-2,6 mm compr., glabros, alvos a esverdeados ou róseos a arroxeados; anteras 1,4-1,8 mm compr., lineares, base sagitada, ápice obtuso a emarginado; ovário 1,2-2 × 0,9-1,2 mm, elíptico, glabro, estilete 4-6,8 mm compr., estigma 2-2,8 mm compr., lanceolado, ápice agudo, papiloso, papilas lanceoladas. Cápsulas 4-5 mm diâm., obcordadas, glabras, metaestilete 1-1,5 mm compr., zona de abscisão elíptica, pericarpo ca. 0,2 mm espessura, epicarpo liso, glabro, castanho, mesocarpo rígido, cartáceo, endocarpo fosco; carpoatlas 3,5-4,2 × 1,6-1,8 $\mathrm{mm}$, rômbico-elíptico, extremidades acuminadas; forame elíptico, 0,9-1 × 0,5-0,6 mm. Sementes 2 por lóculo, 1-2 × 0,8-1 mm, acastanhadas, oblongas a globosas, glabras.

Material examinado: Angra dos Reis, estrada para Angra dos Reis, 29.III.1974, fl., D. Sucre 10664 (HUEFS, RB). Itatiaia, Montserrat, lote 21, I.1938, fl. e fr., M.K.E. Burret \& A.C. Brade 16024 (RB!, Holótipo); lote 17, 13.II.1948, fl., A.C. Brade 18840 (RB). Paraty, divisa entre Rio de Janeiro/São Paulo, limite do município de Paraty/Ubatuba, Morro do Papagaio, 21.XI.1990, fl. e fr., C. Farney 2495 (RB).

Espécie endêmica do Brasil, ocorrendo nos estados da Bahia, Espírito Santo e Rio de Janeiro. Ocorre na Floresta Atlântica, em Floresta Ombrófila Densa Submontana em altitudes de 420-700 m.s.m. Espécie que se desenvolve em local úmido de mata sombria. Coletada com flores em novembro, janeiro, fevereiro e março, e em fruto em janeiro. No estado do Rio de Janeiro ocorre nos municípios de Angra dos Reis, Itatiaia e Paraty (Fig. 10). Spigelia reflexicalyx foi recentemente considerada sinônimo de $S$. amplexicaulis E.F.Guim. \& Fontella (Zappi 2005). A autora afirmou que ao analisar os espécimes-tipo de ambas as espécies, concluiu que estes tratavam-se da mesma espécie em distintas fenofases: $S$. reflexicalyx em flor, e $S$. amplexicaulis em fruto. Entretanto, os dois espécimes apresentam flores e frutos desenvolvidos, como descrito por Guimarães \& Fontella-Pereira (1969). Além disso, as duas espécies podem ser facilmente diferenciadas pelo seguinte conjunto de caracteres: folhas lanceoladas a elípticas, com margem revoluta e base assimétrica, variando de truncada a arredonda (vs. oblongo-lanceoladas, margem plana e base simétrica, variando de amplexicaule a subcordada, em $S$. amplexicaulis); cálice com lacínios reflexos, (vs. eretos); corola alvo-esverdeada com estrias esverdeadas a arroxeadas na face interna da corola, 
lobos ca. 1,9-2,6 mm compr. (vs. completamente alva, lobos 1,2-1,4 mm compr.); anteras ca. 1,4-1,8 mm compr. (vs. ca. 0,7-0,9 mm compr.); e cápsulas glabras, obcordadas, 4-5 mm diâm. (vs. minutamente velutinas, depresso-obcordadas, 3-3,5 × 6-6,5 mm). Assim, no presente trabalho, reestabelecemos $S$. reflexicalyx como uma espécie distinta de $S$. amplexicaulis.

\subsection{Spigelia scabra Cham. \& Schltdl., Linnaea} 1(2): 202.1826.

Figs. 6; 8g

Erva ca. 10-40 cm alt. Caule liso, quadrangular, com alas inconspicuas em direção aos nós, glabros. Estípulas triangulares, escabras, margens escabras. Folhas opostas dísticas a cruzadas, verticiladas no ápice dos ramos, subsésseis; pecíolo 1,5-4,5 mm compr., decurrente, cilíndrico, escabro; lâmina 2,1-4,8 × 1-2 cm, discolor, elíptica, membranácea, bulada, nervuras bem marcadas, glabra, raro escabra, glandulosa, base simétrica, cuneada, margem plana, glabra, ápice arredondado a acutiúsculo. Inflorescência terminal ou axilar, solitária, 4-12-floras, eixo maior ou igual a 0,5 mm compr., reto, quadrangular, delicado. Flores subsésseis, pedicelo 0,5-2 mm compr.; botões 0,8-1 cm compr.; cálice com lacínios ca. 1,5 mm compr., lanceolados à triangulares, ápice agudo a acuminado, livres até $1 / 2$ do compr., glabros externamente, margem glabra; corola alva a rósea, internamente sem estrias, lobos ca. $8 \mathrm{~mm}$ compr., glabros, alvos a róseos a arroxeados; anteras ca. 1,5 mm compr., ovadas, base sagitada, ápice agudo, levemente inclinado; ovário $0,4-0,6 \times 0,4-0,5 \mathrm{~mm}$, obovado a globoso, glabro, estilete 2-2,6 cm compr.; estigma 2,2-3,1 mm compr., lanceolado, ápice agudo, densamente papiloso, papilas lanceoladas. Cápsulas 3-3,6 × 4,8-5 mm, depresso-obcordadas, glabras, metaestilete ca. 0,9-1,4 mm compr., zona de abscisão oblonga; pericarpo ca. 0,2 mm espessura, epicarpo glabro, liso, mesocarpo rígido, cartáceo, endocarpo acetinado, pardo; carpoatlas 2,5-3,2 × 1,5-2 mm, elíptico, extremidades obtusas; forame arredondado, 0,8-1,2 × 0,8-1,1 $\mathrm{mm}$. Sementes 2 por lóculo, ca. 1,5 × 0,5 mm, lanceoladas a oblongas, castanhas, glabras.
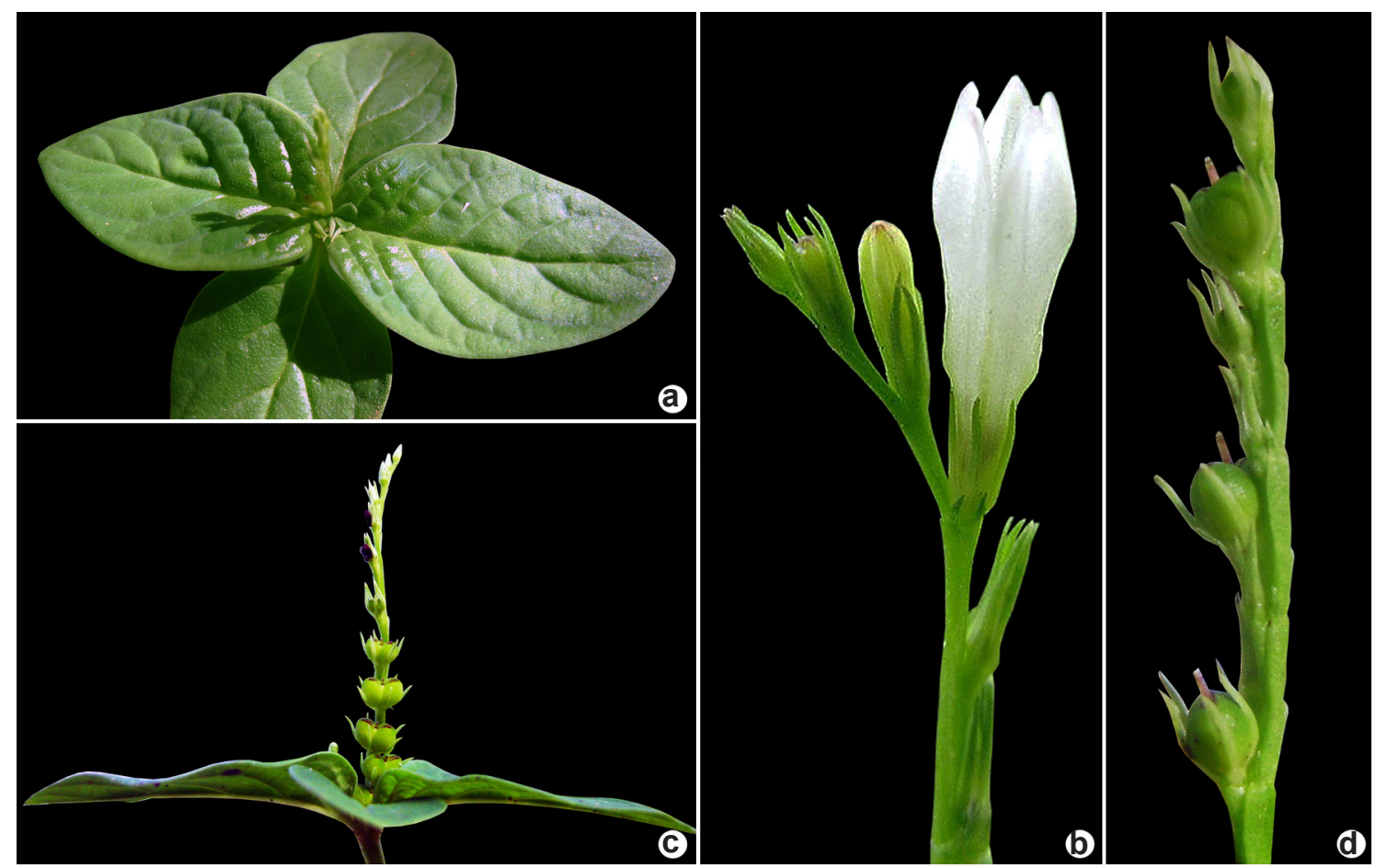

Figura 6 - Spigelia scabra - a. hábito; b. detalhe da inflorescência, mostrando botões florais e uma flor em antese; c. ramo frutífero; d. detalhe da infrutescência, mostrando o eixo quadrangular e as cápsulas imaturas. Fotos: a,c,d. L.S. Cardinelli; b. L.A. Funez.

Figure 6 - Spigelia scabra - a. habit; b. detail of the inflorescence, showing flower buds and a flower at anthesis; c. fruiting branch; d. detail of the infrutescence, showing the quadrangular axis and immature capsules. Photos: a,c,d. L.S. Cardinelli; b. L.A. Funez. 
Material examinado: Campo dos Goytacazes, margem do Rio Doce, 11.XI.1943, fl. e fr., J.G. Kuhlmann 6422 (RB). Guapimirim, Estação Ecológica Estadual de Paraíso, caminho próximo a represa da CEDAE, 6.II.1992, fl. e fr., L.S. Sylvestre et al. 730 (RB); Centro de Primatologia do Rio de Janeiro, margens do rio Paraíso, 8.XI.1984, fl., G. Martinelli \& G. Bromley 10301 (CEPEC, RB). Itatiaia, Serra de Itatiaia, Parque Nacional do Itatiaia, Rio Bonito, IX.1937, fl., Luiz 51 (RB); picada para os Três Picos, Almirante, 16.III.1942, fl. e fr., W.D. Barros 677 (RB); Estrada Macieiras, Km 6, 14.VII.1967, fl. e fr., S. Andrade 966 (RB); trilha do Hotel Simon para os Três Picos, 23.XI.1994, fl., J.M.A. Braga et al. 1615 (RB); Lago Azul próximo da estrada, 14.II.1995, fl. e fr., J.M.A. Braga et al. 1988 (RB); trilha do Hotel Simon para os Três Picos, 14.I.1997, fl. e fr., J.M.A. Braga et al. 3789 (RB). Petrópolis, Cascatinha, XI.1943, fr., O.C. Góes 769 (RB); Caxambu, 22.I.1887, fl. e fr., A. Glaziou 16261 (R). Rio de Janeiro, Restinga da Tijuca, 4.VIII.1867, A. Glaziou 1160 (R); XI.1881, fr.,
P. Schwacke 3346 (RB); 28.X.1838, Markgraf 3090 \& A.C. Brade (RB).

No estado do Rio de Janeiro ocorre nos municípios de Campo dos Goytacazes, Guapimirim, Itatiaia, Petrópolis e Rio de Janeiro (Fig. 9).

Espécie nativa do Brasil, ocorrendo nos estados do Pará, Bahia, Pernambuco, Goiás, Mato Grosso, Mato Grosso do Sul, Espírito Santo, Minas Gerais, Rio de Janeiro, São Paulo, Paraná, Santa Catarina e Rio Grande do Sul (BFG 2015). Spigelia scabra é uma espécie bastante polimórfica, ocorrendo nos biomas Amazônia, Caatinga, Cerrado e Floresta Atlântica, em diferentes tipos de solo, em margens de rios, em áreas rochosas, não raro encontrada também em capoeiras e ambientes antrópicos (Smith et al. 1976). Apresenta caule quadrangular, flores alvas e dispõe de propriedades anti-helmínticas (Fernández Casa 2007) (Fig 6). Coletas durante todo o ano com flores e frutos.
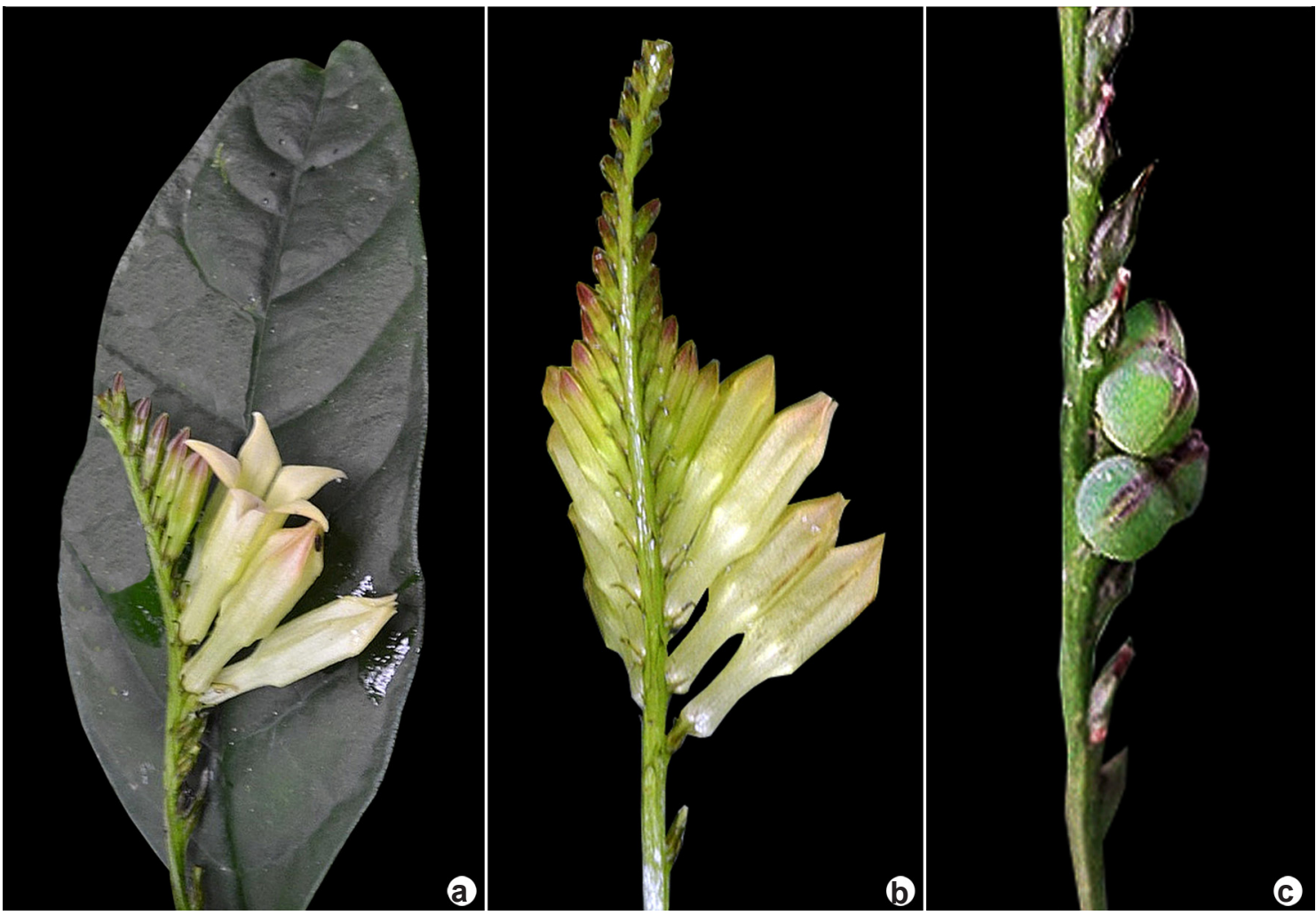

Figura 7 - Spigelia tetraptera - a. detalhe da folha e da inflorescência, mostrando uma flor em antese; b. detalhe da inflorescência, mostrando o eixo delicado e quadrangular e botões em diferentes fases; c. cápsulas em diferentes fases. Fotos: P. Schwirkowski.

Figure 7 - Spigelia tetraptera - a. detail of the leaf and inflorescence, showing a flower at anthesis; b. detail of the inflorescence, showing the thin and quadrangular axis and flower buds in different phases; c. capsules in different phases. Photos: P. Schwirkowski. 

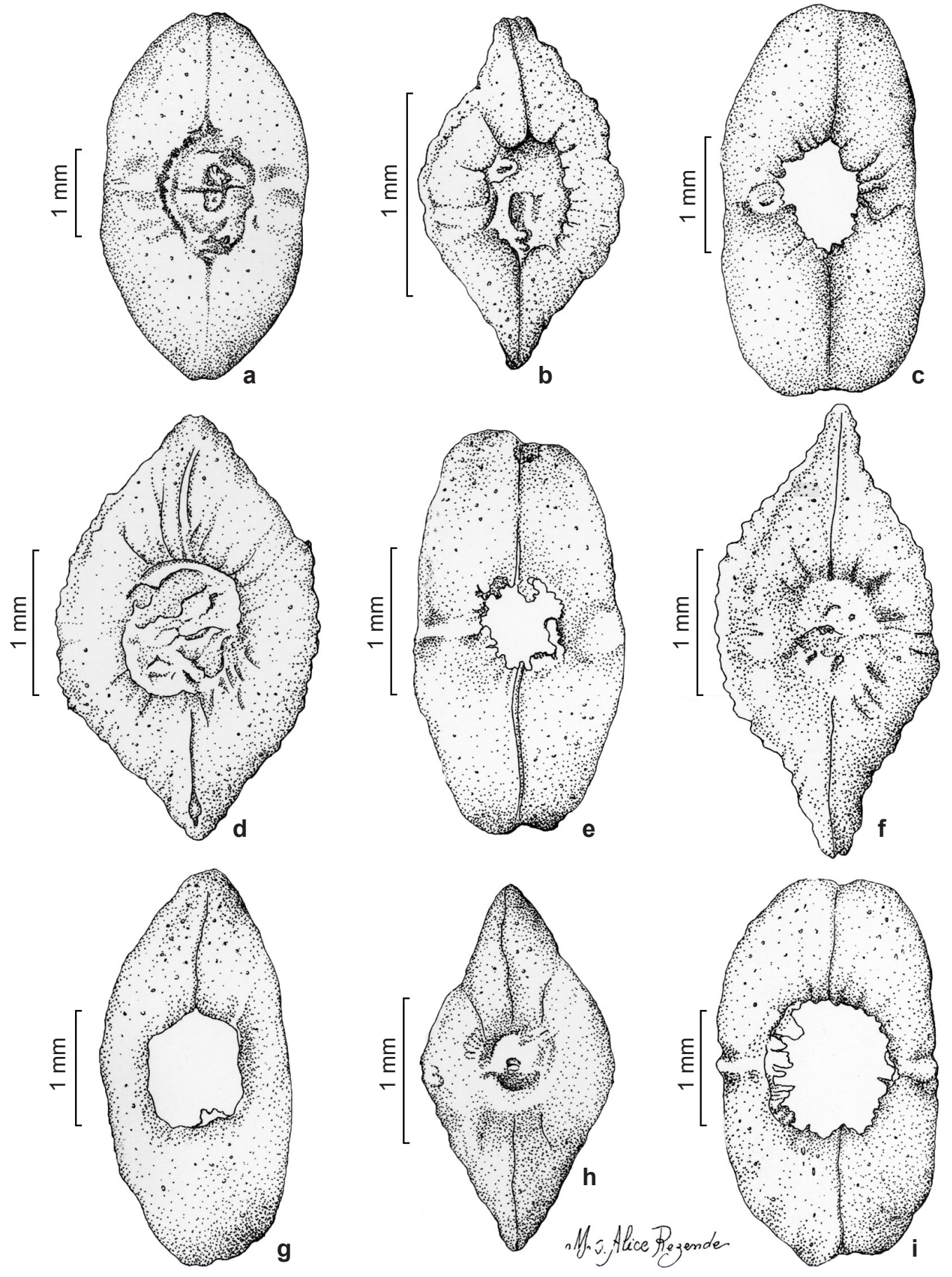

Figura 8 - Morfologia dos carpoatlas das espécies de Spigelia do Rio de Janeiro - a. S. beyrichiana; b. S. flemmingiana; c. S. laurina; d. S. macrophylla; e. S. pusilla; f. S. reflexicalyx; g. S. scabra; h. S. schlechtendaliana; i. S. tetraptera. (a. J.F.A. Baumgratz 379, RB; b. R. Marquete 1599, RB; c. J.G. Kuhlmann s.n., RB 137542; d. A.C. Brade 10459, R; e. A.C. Brade 10859, R; f. Burret \& A.C. Brade 16024, RB holótipo; g. A. Glaziou 16261, R, RB; h. T.B. Cavalcanti et al. CFSC 9603, SPF; i. A.B. Pereira 55, HUEFS, RB). Ilustrações: M.A. Rezende.

Figure 8 - Morphology of the carpoatlas of Spigelia species from the state of Rio de Janeiro - a. S. beyrichiana; b. S. flemmingiana; c. S. laurina; d. S. macrophylla; e. S. pusilla; f. S. reflexicalyx; g. S. scabra; h. S. schlechtendaliana; i. S. tetraptera. (a. J.F.A. Baumgratz 379, RB; b. R. Marquete 1599, RB; c. J.G. Kuhlmann s.n., RB 137542; d. A.C. Brade 10459, R; e. A.C. Brade 10859, R; f. Burret \& A.C. Brade 16024, RB holótipo; g. A. Glaziou 16261, R, RB; h. T.B. Cavalcanti et al. CFSC 9603, SPF; i. A.B. Pereira 55, HUEFS, RB). Illustrations: M.A. Rezende. 
1.8. Spigelia schlechtendaliana Mart., Nov. Gen. Sp. Plant. 2:129.1826.

Fig. $8 \mathrm{~h}$

Erva a subarbusto ca. $30-50 \mathrm{~cm}$ alt. Caule liso, quadrangular, sem alas, glabro. Estípulas triangulares, margens glabras ou ciliadas. Folhas opostas-dísticas, verticiladas no ápice dos ramos, subsésseis; pecíolo 0,8-2 mm compr., decurrente, cilíndrico, pubescente; lâmina ca. 1,3 × $3 \mathrm{~cm}$, concolor, elíptica a lanceolada, membranácea, bulada, nervuras bem marcadas, glandulosa em ambas as faces, base simétrica, cuneada, margem plana, ciliado-papilosa, ápice agudoacuminado. Inflorescências terminal ou axilar, agrupadas, 4-20-floras, eixo maior ou igual a 0,5 $\mathrm{mm}$ compr., reto, quadrangular, delicado. Flores subsésseis, pedicelo $0,5-1 \mathrm{~mm}$ compr.; botões 0,5-1,3 cm compr.; cálice com lacínios ca. $1 \mathrm{~mm}$ compr., eretos, lanceolados, glabros em ambas as faces, livres até $4 / 5$ do compr., ápice agudo a acuminado; corola alva, internamente com estrias róseas a arroxeadas, lobos ca. $1 \mathrm{~cm}$ compr., glabros, róseos a arroxeados; anteras ca. 1,4 mm compr., ovadas, base sagitada, ápice agudo; ovário 0,6-1,3 mm diâm., globoso, glabro, estilete 1,1-2 mm compr.; estigma 3,5-4,4 mm compr., lanceolado, ápice agudo, densamente papiloso, papilas lanceoladas à triangulares. Cápsulas 2,5-5 $\times 2-2,5 \mathrm{~mm}$, depresso-obcordadas, glabrescentes a esparsamente pubescentes, metaestilete $0,8-1$ mm compr., zona de abscisão elíptica, pericarpo ca. 0,05 $\mathrm{mm}$ de espessura, epicarpo glabro, liso, mesocarpo rígido, cartáceo, endocarpo acetinado, pardo; carpoatlas $2-2,7 \times 1,5-1,8$ $\mathrm{mm}$, rômbico-elíptico, extremidades agudas, forame arredondado, ca. $1 \times 1 \mathrm{~mm}$. Sementes 2 por lóculo, ca. $1,5 \mathrm{~mm}$ diâm., nigrescentes, globosas, glabras.

Material examinado: Santa Maria Madalena, subida da Pedra Dubois, 22.XI.1999, fl., D.C. Zappi et al. 380 (UEC).

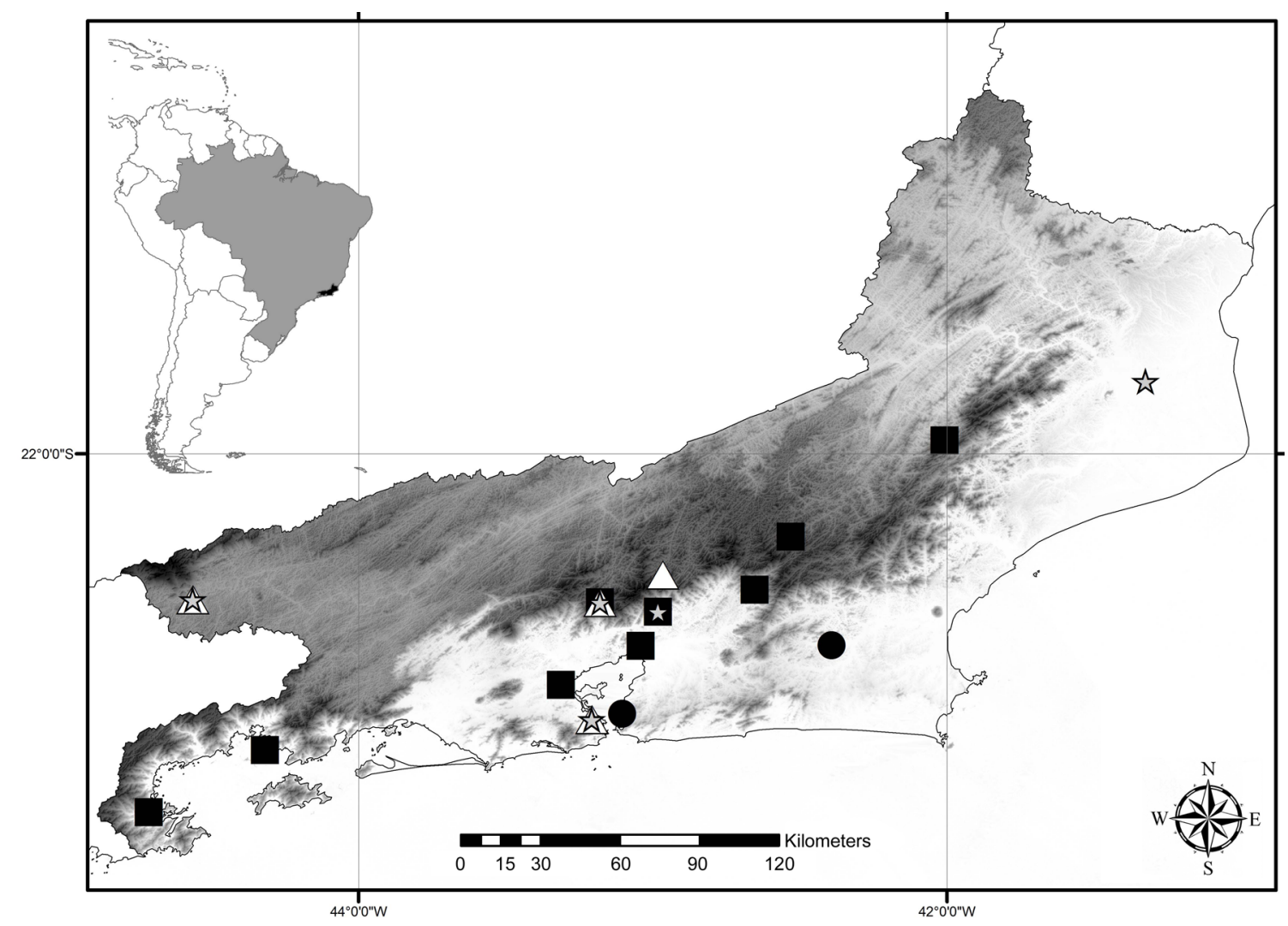

Figura 9 - Mapa de distribuição de alguma das espécies de Spigelia ocorrentes no estado do Rio de Janeiro - $S$. beyrichiana $(\boldsymbol{\square})$; S. flemmingiana $(\bullet)$; S. laurina $(\Delta)$; S. scabra (ઐ); S. schlechtendaliana $(\boldsymbol{\Delta})$.

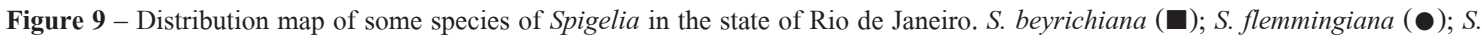

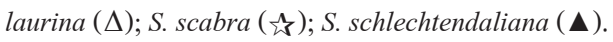


Material adicional examinado: BRASIL. MINAS GERAIS: Monte Azul, Serra do Espinhaço, 14.III.1995, fl., M. Hatschbach \& J.M. Silva 61869 (B, MBM). Santana do Riacho, Serra do Cipó, Reserva do IBDF, caminho para a Cachoeira da Farofa, 21.II.1986, fl. e fr., T.B. Cavalcanti et al. CFSC 9603 (SPF).

Espécie nativa do Brasil, ocorrendo nos estados do Mato Grosso, Goiás, Bahia, Espírito Santo, Minas Gerais, Rio de Janeiro e São Paulo (BFG 2015). Habita o Cerrado e a Floresta Atlântica, em locais úmidos próximos a córregos ou em áreas campestres. No estado do Rio de Janeiro foi registrada apenas para o município de Santa Maria Madalena (Fig. 9). Spigelia schlechtendaliana possui flores com corola alva, com estrias róseas a arroxeadas, e lobos róseos a arroxeados, carpoatlas rômbico-elíptico com extremidades agudas e pericarpo de espessura inferior ao das outras espécies deste estudo. Coletada em flor em janeiro, março, maio, novembro e dezembro.
1.9. Spigelia tetraptera Taub. ex L.B.Sm., Bull. Soc. Bot. France 57: 468. 1910. Figs. 7; 8i

Erva 35-75 cm alt. Caule estriado, quadrangular, com alas evidentes em direção aos nós, escabro ou glabro. Estípulas triangulares, glabras ou pilosas na face abaxial. Folhas opostasdísticas ou cruzadas, verticiladas no ápice dos ramos, pecioladas; pecíolo 3,0-6 cm compr., decurrente, cilíndrico, glabro ou levemente escabro; lâmina 3,1-10,7 × 0,9-3,1 cm, discolor, lanceolada a oblongo-lanceolada, membranácea, bulada, nervuras bem marcadas, glabra, raro escabra, base simétrica, cuneada ou arredondada, margem plana, ciliada, ápice agudo a acuminado. Inflorescência terminal ou axilar, solitária, 7-21-floras, eixo maior ou igual a $0,5 \mathrm{~mm}$ compr., reto, quadrangular, delicado. Flores subsésseis, pedicelo 2-3 mm compr.; botões 1,4-1,8 cm compr.; cálice com lacínios 0,5-1 mm compr.,

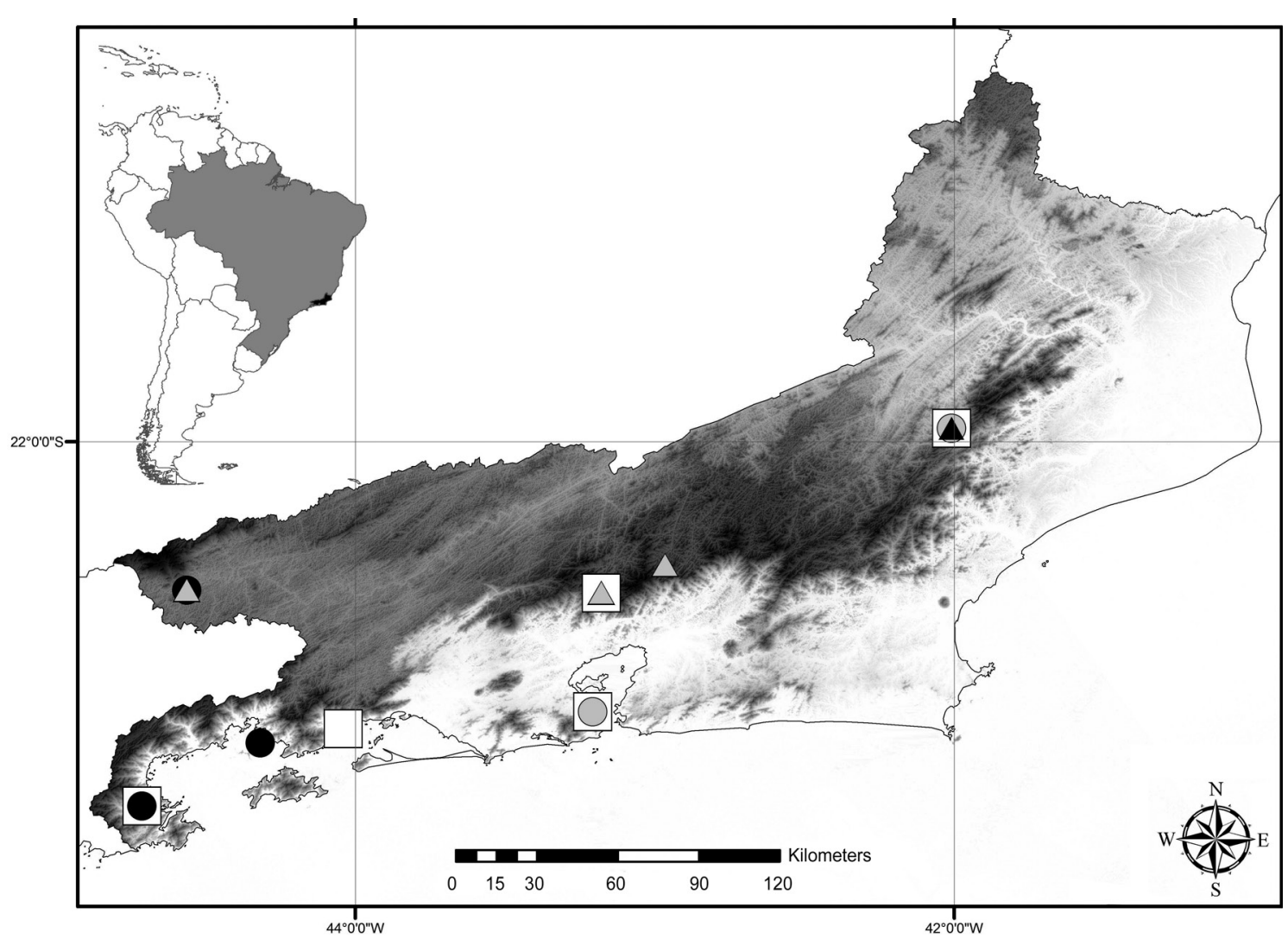

Figura 10 - Mapa de distribuição de alguma das espécies de Spigelia ocorrentes no estado do Rio de Janeiro - $S$. macrophylla $(\square)$; S. pusilla $(\bigcirc)$; S. reflexicalyx $(\bullet)$; S. tetraptera $(\Delta)$.

Figure 10 - Distribution map of some species of Spigelia in the state of Rio de Janeiro - S. macrophylla $(\square)$; S. pusilla (O); S. reflexicalyx $(\bullet)$; S. tetraptera $(\Delta)$. 
eretos, ovado-lanceolados, glabros ou escabros, livres até $1 / 2$ do compr., margem ciliada ou glabra, ápice agudo a acuminado; corola alva a creme a rósea, internamente sem estrias, lobos 0,3-2,1 cm compr., glabros, creme ou róseos a avermelhados ou arroxeados; anteras ca. 1,9 mm compr., oblongas, base cordada, ápice agudo; ovário 1-1,4 mm diâm., globoso, glabro, estilete 1,9-2,6 mm compr., estigma 2,2-3,5 mm compr., lanceolado, ápice agudo, densamente papiloso, papilas triangulares. Cápsulas 3-5,2 × 3,5-7 $\mathrm{mm}$, obcordadas a depresso-obcordadas, glabras, metaestilete ca. 1,2-2 mm compr., zona de abscisão elíptica, pericarpo ca. 0,2 mm espessura, epicarpo liso, glabro, castanho, mesocarpo rígido, cartáceo, endocarpo brilhante; carpoatlas 3-3,7× 1,8-2 mm, elíptico, extremidades emarginadas; forame arredondado, $1-1,2 \times 0,8-1 \mathrm{~mm}$. Sementes 2 por lóculo, ca. 1,6 $\times 0,9 \mathrm{~mm}$, nigrescentes, oblongas, glabras.

Material examinado: Itatiaia, 5.I.1896, E. Ule 618 (R); Córrego Taquaral, 7.X.1945, fl. e fr., A.B. Pereira 55 (HUEFS, RB); south face of Mt. Itatiaia, in valley of the creek, Rio Campo Belo, 2,9 $\mathrm{km}$ along road above Maromba, 1.XI.1965, fl. e fr., G. Eiten \& L.T. Eiten 6459 (NY, SP, UB); Km 13, 1948, fl. e fr., P. Occhioni 1210 (RB); subida ao Planalto, 10.I.1975, fl. e fr., G. Hatschbach et al. 35825 (MBM); 10.X.1977, fl. e fr., P.J.M. Maas 3160 (NY, RB); entre Montserrat e Maromba, 17.X.1922, J.G. Kuhlmann (RB 25585); sítio do Walter, V.1926, A. Sampaio 4664 (R); Macieiras, VII.1930, fl., A.C. Brade 12660 (RB); Km 14, 8.I.1947, fl. e fr., A.P. Duarte 875 (RB); Km 13m 1948, fr., P. Occhioni 1210 (RB); Rio do Funil, próximo do estado de São Paulo, 6.XI.1956, fl., M. Kuhlmann 4011 (SP). Petrópolis, Mata do Judeu, 24.XI.1968, fl. e fr., D. Sucre \& P.I.J. Braga 4191 (RB); Morro do Carangola, 22.XII.1982, A. Glaziou 14100 (B! Holótipo; F!, G, K, $\mathrm{P}, \mathrm{R}$ !). Teresópolis, Parque Nacional Serra dos Órgãos, Castelos, s.d., A. Brade 10911 (R); Km 5,5 e 6,5, 8.XII. 1970, J. Bacia 185 \& J. Augusto (R); caminho para a pedra do sino, 2.XI.1952, s.leg. (R); 7.III.1956, E. Pereira 1904 (RB); Picada do campo das Antas, 30.XI.1942, fl., E. Pereira 250 (RB); 7.III.1956, fl., E. Pereira 1904 (RB).

Espécie endêmica do Brasil, ocorrendo nos estados do Amazonas, Pará, Mato Grosso do Sul, Bahia, Minas Gerais, Espírito Santo, Rio de Janeiro, São Paulo, Paraná e Santa Catarina (BFG 2015). Habita a Amazônia, Cerrado e a Floresta Atlântica, crescendo em Floresta Ombrófila e Restinga, mata secundária e margem de florestas, em altitude de 800-1700 m.s.m. No estado do Rio de Janeiro ocorre nos municípios de Itatiaia, Petrópolis e Teresópolis
(Fig. 10). Spigelia tetraptera apresenta flores alvas a creme a róseas, com lobos creme ou róseos a avermelhados ou arroxeados, caules quadrangulares e inflorescência solitária (Fig. 7). Encontrada em floração e frutificação em outubro, novembro, fevereiro, abril e junho.

\section{Agradecimentos}

A pesquisa foi financiada pelo $\mathrm{CNPq}$ e pela Petrobrás (610.4.025.02.3/Programa Mata Atlântica - Jardim Botânico do Rio de Janeiro). Os autores agradecem aos curadores dos herbários consultados. A Luiz Moraes, as sugestões no manuscrito; a Rafael Felipe de Almeida, as sugestões em uma versão inicial do manuscrito, auxílio na edição das figuras e confecção do mapa. Os autores também agradecem a Maria Alice Rezende, as ilustrações. A I.G. Costa, P. Schwirkowski, L.S. Cardinelli e L.A. Funez, as fotos de campo das espécies de Spigelia. E a Dra. Marli Pires e dois revisores anônimos, as importantes contribuições para a melhoria do presente trabalho.

\section{Referências}

Backlund M, Oxelman B \& Bremer B (2000) Phylogenetic relationships within the Gentianales based on $\mathrm{ndhF}$ and $\mathrm{rbcL}$ sequences, with particular reference to the Loganiaceae. American Journal of Botany 87: 1029-1043.

BFG - The Brazil Flora Group (2015) Growing knowledge: an overview of seed plant diversity in Brazil. Rodriguésia 66: 1085-1113.

Cronquist A (1981) An integrated system of classification of flowering plants. Columbia University Press, New York. 1262p.

Fernández Casa FJ (2003) Estudios carpológicos en el género Spigelia (Spigeliaceae). Collectanea Botanica (Barcelona) 26: 5-46.

Fernández Casa FJ (2007) Spigeliarum notulae $S$. scabra Chamisso \& Schlechtendal (Spigeliaceae). Adumbrationes ad Summae Editionem 22: 1-140.

Guimarães EF \& Fontella-Pereira J (1969) Contribuição ao estudo do gênero Spigelia L. III. Sinopse das espécies que ocorrem no Brasil. Loefgrenia 34: $1-18$.

Heywood VH, Brummitt RK, Culham A \& Seberg O (2007) Flowering plant families of the world. Royal Botanic Gardens, Kew. 424p.

Hickey LJ (1974) Clasificación de la arquitectura de las hojas de dicotiledóneas. Boletín de la Sociedad Argentina de Botánica 16: 1-26.

IBGE - Instituto Brasileiro de Geografia e Estatística (2012) Manual técnico da vegetação brasileira: sistema fitogeográfico, inventário das formações 
florestais e campestres, técnicas e manejo de coleções botânicas, procedimentos para mapeamentos. $2^{\text {a }}$ ed. Vol. 1. IBGE, Rio de Janeiro. $272 p$.

Progel A (1868) Loganiaceae. In: Martius CFP (ed.) Flora Brasiliensis. Frid. Fleischer, Monique. Vol. 6, pars 1, pp. 249-300.

Rizzini CT (1977) Sistematização terminológica da folha. Rodriguésia 29: 103-125.

Smith LB, Guimarães EF, Fontella-Pereira J \& Norman EM (1976) Loganiáceas. In: Reitz R (ed.) Flora Ilustrada Catarinense, I Loga. Herbário Barbosa Rodrigues, Itajaí. Pp 1-77.

The Plant List (2013) Version 1.1. Published on the Internet. Disponível em <http://www.theplantlist. org/>. Acesso em 30 novembro 2015.
Thiers B [continuamente atualizado] Index Herbariorum: A global directory of public herbaria and associated staff. New York Botanical Garden's Virtual Herbarium. Disponível em $<$ http://sweetgum.nybg. org/science/ih/>. Acesso em 30 novembro 2015.

Vellozo JMC [1825] (1829) Florae Fluminensis. Typographia Nationali, Rio de Janeiro. 352p.

Vellozo JMC [1827] (1831) Florae Fluminensis Icones. Vol. 2. Lithogr. Senefelder, Paris. 157p.

Zappi DC (2005) Loganiaceae. In: Wanderley MGL, Shepherd GJ, Giulietti AM, Melhem TS, Bittrich V \& Kameyana C (eds.) Flora Fanerogâmica do estado de São Paulo. Instituto de Botânica, São Paulo. Vol. 4, pp. 261-271.

Zappi DC (2006) Flora da Reserva Ducke, Amazonas, Brasil: Loganiaceae. Rodriguésia 57: 193-204. 